\title{
CUOTAS DE PESCA Y LIBRE COMPETENCIA: CONSIDERACIONES PARA LA NUEVA LEY DE PESCA*
}

\author{
Juan Pablo Montero \\ Universidad Católica de Chile
}

\begin{abstract}
Resumen: Hacia fines del 2012 debe entrar en vigencia una nueva ley de pesca en reemplazo de la actual Ley $\mathrm{N}^{\circ} 19.713$. Varios analistas han argumentado que la nueva ley se debe hacer cargo, entre otras cosas, de la baja competencia en el sector y de la falta de entrada de nuevos actores. El objetivo de este trabajo es documentar precisamente lo contrario a la luz de la teoría económica y de la evidencia proveniente de las pesquerías de la zona centro-sur. Este resultado acarrea dos
\end{abstract}

Juan Pablo Montero. Ph.D. Instituto Tecnológico de Massachusetts (MIT). Profesor titular del Instituto de Economía de la Pontificia Universidad Católica de Chile. Ha sido profesor visitante del Sloan School of Management del MIT, de la Escuela de Gobierno de Harvard University e investigador asociado al Center for Energy and Environmental Policy Research del MIT. Dirección electrónica: jmontero@uc.cl.

* Debo mencionar que preparé un estudio por encargo de Asipes en los temas que aquí se abordan para ser presentado al Tribunal de la Libre Competencia en el 2010. Éste ha sido el único trabajo remunerado en materia pesquera que he realizado en los últimos cinco años. No tengo acciones de compañías en el sector pesquero ni participo de ningún directorio. Quiero agradecer además a Cristóbal Eyzaguirre, Julio Peña, Rodrigo Sarquis, a dos árbitros anónimos de Estudios Públicos y al co-editor Sergio Urzúa por sus comentarios y/o discusiones. Por último, las opiniones que aquí se expresan son de mi exclusiva responsabilidad y no comprometen de manera alguna a las personas e instituciones nombradas anteriormente.

Estudios Públicos, 127 (invierno 2012). 
implicancias para la nueva ley. La primera es que el uso de licitaciones como mecanismo de asignación de cuotas debiera ser justificado como un objetivo de distribución y no de eficiencia; y la segunda es que no hay problemas de eficiencia en asignar cuotas a perpetuidad en la medida que sean fácilmente transferibles.

Palabras clave: cuotas de pesca, licitaciones, libre competencia. Clasificación JEL: L41, Q22.

Recibido: diciembre 2011; aceptado: julio 2012.

\section{FISHING QUOTAS AND COMPETITION:} CONSIDERATIONS FOR THE NEW CHILEAN FISHING LAW

Abstract: A new fishing law is to enter into effect by the end of 2012 to replace the actual law 19,713. Several analysts have argued that the new law must correct, among other things, for the limited competition and lack of new entry in the sector. Using economic theory and evidence from fisheries in Chile's central-south zone, the objective of this paper is to document precisely the contrary. The latter has two implications for the drafting of the new law. The first is that the use of auctions to allocate quotas should only be justified on distribution grounds and not on efficiency grounds; and second, that there are no efficiency losses from allocating quotas in perpetuity provided that they are easily transferable.

Keywords: fishing quotas, auctions, competition.

Clasification JEL: L41, Q22.

Received: December 2011; accepted: July 2012.

\section{Introducción}

$\mathrm{H}$

acia fines del 2012 debe entrar en vigencia una nueva ley de pesca en reemplazo de la actual Ley $\mathrm{N}^{\circ} 19.713$. Varios analistas han argumentado que la nueva ley se debe hacer cargo, entre otras cosas, de la baja competencia en el sector y de la falta de entrada de nuevos actores. Argumentos de este tipo quedan bien sintetizados en una reciente consulta al Tribunal de Defensa de la Libre Competencia (TDLC), donde se le reclama la necesidad de que se "...establezca las condiciones para que se materialice la efectiva entrada de competencia al mercado de la pesca industrial, por la vía de exigir la real aplicación, por parte de la Subsecretaría de Pesca (Subpesca), del artículo 27 de la Ley de Pesca 18.892 
(LGPA), cuerpo normativo que contempla la subasta anual de permisos extraordinarios de pesca, con el objeto de renovar parcialmente, cada año, a los actores con permisos de pesca presentes en el mercado, cuestión que hasta la fecha Subpesca se ha negado a efectuar"1.

En lo esencial, desde un punto de vista económico, los argumentos detrás de la "falta de competencia" se pueden agrupar en dos. Primero, que varias de las pesquerías del país, incluyendo las de la zona centro-sur, sufren de problemas de competencia por las dificultades que nuevos y/o menores actores enfrentan al querer entrar y/o expandir su participación en dichos mercados. Este argumento está basado en la idea de las "barreras a la entrada" que se generan al entregar a perpetuidad, o por un tiempo prolongado, un insumo esencial, como son las cuotas individuales de pesca, a un grupo determinado de actores, los que no tendrían ningún incentivo para transferir dichas cuotas a terceros por la supuesta erosión en el poder de mercado que sufrirían.

Lo segundo es que la solución a estos problemas de competencia pasa por subastar las cuotas individuales de pesca; pero no de cualquier forma, sino de una forma que asegure la entrada de nuevos actores y/o la expansión de actores existentes de menor tamaño. Hay algunos que incluso recomiendan no usar sólo el precio (i.e., ofertas de las firmas) como variable de asignación en la subasta sino otras variables que aseguren la entrada de actores menores.

El objetivo de este estudio es precisamente analizar la validez de estos dos argumentos a la luz de la teoría económica y de los hechos observados. Para tal efecto, en la sección 2 se desarrolla un marco teórico que nos permita identificar el tipo de problemas de libre competencia que pueden aquejar específicamente a los mercados de pesca. En la sección 3 llevo el marco teórico a los datos de la zona centro-sur en busca de evidencia que permita rechazar o confirmar la hipótesis de falta de competencia que varios levantan. A pesar de no encontrar problemas de competencia, en la sección 4 igualmente discuto si es efectivo, y de qué forma, que un mecanismo de subasta de cuotas individuales de pesca pueda aliviar dichos problemas, en caso de existir. En la sección 5 concluyo con un resumen con los principales resultados del estudio.

${ }^{1}$ Tomado textualmente del escrito presentado por la compañía pesquera Lota Protein al TDLC. El escrito completo se encuentra en www.tdlc.cl. 


\section{Competencia en pesca: Un marco teórico}

En cualquier análisis de competencia es útil tener claro un par de condiciones. La primera es eficiencia productiva (productive eficiency en inglés) y se cumple cuando una determinada producción por un grupo de firmas se realiza a mínimo costo. En presencia de economías de escala, la eficiencia productiva puede requerir que sean unas pocas las firmas que producen. La segunda condición es la de eficiencia asignativa (allocative efficiency en inglés) y en términos generales se cumple cuando los precios están alineados con los $\operatorname{costos}^{2}$. En mercados competitivos se cumplen ambas condiciones. Se cumple la primera porque, de no ser así, las firmas más eficientes (i. e., con menores costos) reemplazarían producción de las menos eficientes. Y se cumple la segunda porque de no ser así habría firmas que tendrían incentivos para expandir la producción o entrar a producir. Habría un rol para la autoridad de competencia en la medida que una o ambas de estas condiciones no se cumplan. En general las autoridades de competencia prestan mucho más, si no exclusiva, atención al cumplimiento de la segunda condición que a la primera.

Quizá un buen punto de partida para discutir temas de competencia más específicos a la industria pesquera es el reciente trabajo de Peña-Torres y Fernández (2009), PT\&F de aquí en adelante, donde se analizan los incentivos que firmas existentes (o "incumbentes") tendrían para disuadir la entrada de potenciales rivales en subastas donde se licita una fracción, en general menor, de la cuota global de pesca. Más allá de sus resultados particulares, el paper es útil porque toca varios elementos que permiten estructurar un marco teórico para estudiar la competencia en la industria pesquera. Es importante aclarar, sin embargo, que el marco teórico que se desarrolla a continuación se hace bajo el supuesto que las cuotas individuales de pesca ya fueron asignadas a las firmas - con algún criterio histórico posiblemente. En la sección 4 extendemos la discusión hacia criterios de asignación iniciales incluyendo subastas.

${ }^{2}$ Para muchos la eficiencia asignativa exige que los precios sean iguales a los costos marginales; para otros es suficiente con que no haya rentas sobrenormales. No vale la pena ahondar en este punto para lo que nosotros necesitamos. 


\subsection{La libre entrada es socialmente ineficiente}

La construcción del marco teórico parte, a diferencia de lo que ocurre en la mayoría de los mercados que conocemos, con el reconocimiento de que es socialmente ineficiente permitir libre entrada en pesquerías abiertas con riesgo de sobre-explotación, como las que nos interesan en este estudio. Tal como lo demuestra la experiencia en Chile y en el mundo, la libre entrada a este tipo de pesquería lleva necesariamente a una "tragedia de los comunes", esto es, a una (sobre)explotación por encima de lo que es sustentable en el largo plazo. Y la razón es simple. Una compañía realizará esfuerzo pesquero hasta el punto en donde su utilidad económica sea igual a cero. Si bien esta condición asegura eficiencia económica en muchos mercados, es insuficiente en una pesquería, ya que desconoce la externalidad física (no pecuniaria) que un nuevo entrante al mercado impone en el resto de los pescadores al reducir su productividad a causa de la menor disponibilidad de peces. En rigor, uno quisiera limitar la entrada (en el largo plazo) al punto donde el costo de la última unidad de esfuerzo pesquero sea igual a los beneficios que reporta. Con esto se maximiza el valor presente del recurso pesquero (Clark, 1990). Por lo mismo, muchas veces se dice que la manera socialmente óptima de administrar una pesquería cuyos productos se transan en un mercado internacional competitivo es entregando la pesquería a un solo dueño.

En la práctica, el límite a la entrada para una pesquería con riesgo de sobre-explotación se establece fijando una cuota global de pesca - la que típicamente se ajusta año a año según la disponibilidad del recurso. La forma de asignar esta cuota global entre las distintas compañías pesqueras puede tomar varias formas, desde la no asignación individual (dando paso a lo que comúnmente se conoce como "carrera olímpica"), pasando por cuotas individuales no transferibles, hasta cuotas individuales transferibles, como ocurre con varias pesquerías en países como Chile, Nueva Zelanda e Islandia. Es difícil muchas veces trazar una línea entre lo que es transferible y lo que no es. Es importante, eso sí, mencionar que la no asignación individual introduce otro problema: la sobre-inversión en esfuerzo pesquero para capturar lo más posible de la cuota global. Las cuotas individuales permiten resolver este problema de sobre-inversión o baja productividad, tal como documentan GómezLobo et al. (2007) para el caso de Chile. Es por esto que en el resto del estudio nos concentraremos en cuotas individuales transferibles. 


\subsection{No es necesario pagar por las cuotas de pesca}

Un segundo conjunto de elementos en este marco teórico tiene relación con la forma de asignar la cuota global entre las potenciales compañías pesqueras. Y aquí aparecen varias preguntas del ámbito de la libre competencia y en última instancia del uso eficiente de los recursos. ¿Debieran las compañías pagar por las cuotas individuales que reciben? ¿Es importante el número de participantes que finalmente reciben cuotas individuales? ¿Debiera permitirse la libre transferencia de las cuotas individuales?, etc. En esta subsección nos ocuparemos de la primera pregunta, acerca de si las compañías debieran pagar o no por las cuotas que reciben. Las otras preguntas las abordaré en secciones posteriores.

No me importa en esta parte el origen del precio de las cuotas, sea éste un precio exógeno fijado por la autoridad o uno endógeno que se despeja en una subasta. Para responder esta pregunta es útil hacer un paralelo con otros recursos que sufren de la "tragedia de los comunes", por ejemplo, el aire limpio, y donde también se ha optado en muchos casos por regular con permisos de contaminación muy similares a las cuotas de pesca (Tietenberg, 2003). Es muy sabido que en ausencia de regulación, los distintos agentes económicos (i.e., consumidores y empresas) sobre-explotan el recurso aire limpio generando contaminación por encima del óptimo social. Hay básicamente dos formas de internalizar eficientemente la contaminación, fijar un impuesto o entregar cuotas de contaminación. Spulber (1985) demostró que los dos instrumentos son equivalentes para alcanzar el óptimo social siempre y cuando las cuotas sean subastadas, es decir, vendidas por la autoridad. La recaudación de fondos no es lo importante aquí, sino que los agentes económicos paguen directamente por el uso del recurso aire limpio; en caso contrario, habría excesiva entrada de agentes a la economía puesto que no estarían pagando por un insumo dentro de su proceso de producción.

Hay que ser muy claro en esto. La razón por la cual Spulber (1985) explica que es socialmente eficiente que los agentes económicos paguen por la contaminación que generan (ya sea comprando cuotas o pagando un impuesto) es para lograr tanto eficiencia de corto plazo (costo marginal de abatir contaminación igual al beneficio marginal que 
reporta) como eficiencia de largo plazo (tener el número socialmente óptimo de compañías operando en el mercado) ${ }^{3}$.

Hay una diferencia fundamental, sin embargo, entre las cuotas de pesca y los permisos de contaminación que impide extrapolar el resultado de Spulber (1985) a una pesquería. En el caso de la contaminación, una firma que produce pan y emite material particulado, por ejemplo, tiene dos variables de decisión: cuánto pan producir y cuánto material particulado emitir (en otras palabras, la contaminación es un insumo que entra en proporciones variables en la función de producción de la firma). Podría por ejemplo optar por no producir más, o producir lo mismo que antes de la regulación pero instalar equipos (v.gr., filtros) que eliminen la contaminación por completo, o no instalar ningún equipo y comprar permisos de contaminación. La cantidad de entrada al mercado del pan no se fija con la cuota de contaminación, sólo indirectamente con el precio de la contaminación.

La situación en una pesquería es muy distinta, ya que la cuota se asigna sobre un recurso que entra en proporciones fijas en la producción del bien final. Esto significa que al fijar la cuota de pesca se está automáticamente fijando el volumen de producto final que genera esa pesquería $^{4}$. La respuesta entonces a la pregunta de si la autoridad debiera vender las cuotas individuales de pesca es negativa; no hay razones de eficiencia económica para hacerlo. Ahora bien, la autoridad podría igualmente optar por subastar las cuotas si busca recaudar fondos, materia a la que volveremos en la sección 4 del estudio.

\subsection{La estructura de mercado puede ser irrelevante}

Pasemos ahora a revisar la pregunta de si es importante el número de agentes que reciben cuotas individuales en una pesquería en particular. Para abstraerse de otros elementos que revisaremos más

${ }^{3}$ Puede existir una razón adicional para querer recaudar fondos y que tiene relación con el uso de estos recursos para reducir otros impuestos distorsionadores en la economía (Bovenberg y Goulder, 1996). En este estudio me voy a restringir a un análisis de equilibrio parcial, por lo tanto voy a obviar estos argumentos de equilibrio general.

${ }^{4}$ Es cierto que una compañía puede decidir cómo repartir lo capturado entre distintos productos finales ( $v . g r$, harina, aceite, conservas, congelados), pero la esencia del argumento no cambia. 
adelante, incluyendo la transferibilidad, es útil suponer por un momento que todos los agentes son iguales y que tienen costos marginales constantes de explotación. Con esto nos aseguramos eficiencia productiva y nos concentramos en cómo puede ser afectada la eficiencia asignativa. Una de las observaciones de PT\&F para el mercado del bacalao de profundidad (conocido en los mercados internacionales como Chilean sea bass) es que las compañías que actualmente poseen cuotas sólo utilizan una fracción de ellas (las cuotas individuales en este mercado fueron subastadas, pero eso no es relevante para lo que viene a continuación). PT\&F explican que en ninguno de los años comprendidos en el período 1992-2002 los adjudicatarios de cuotas de pesca en Chile usaron el $100 \%$ de las cuotas obtenidas. El porcentaje promedio de uso en este período, a nivel agregado, fue de 72,6\%. En algunos años se usó en torno al $80-95 \%$ del tonelaje total asignado a las compañías, mientras que en otros se usó menos del 50\%. Hay dos hipótesis que pueden explicar una captura por debajo de la cuota asignada. La primera es una menor disponibilidad del recurso ya sea por razones físicas y/o económicas - cuando los precios internacionales no alcanzan a cubrir los costos de explotación de una pesquería en particular. Una segunda hipótesis, que corresponde a la premisa sobre la cual PT\&F desarrollan su trabajo, es que las compañías que operaban en Chile (y también en varias otras partes del mundo) eran lo suficientemente grandes como para hacer uso de su poder de mercado y restringir la oferta por debajo de la cuota asignada en pos de obtener mejores precios por el producto final en el mercado internacional.

Sin entrar a discutir su validez, la premisa de PT\&F es útil para nuestra discusión, ya que plantea la posibilidad de que el número de agentes que finalmente reciben cuotas, independiente de la forma de asignación, puede tener implicancias para la libre competencia, en el sentido de que hay una restricción a la venta del producto final con perjuicios para el consumidor. Es decir, no se cumple la condición de eficiencia asignativa. Hay varias reacciones al respecto. La primera es que esta forma de afectar la libre competencia es altamente específica a la pesquería bajo consideración. Puede haber pesquerías en que aun cuando la totalidad de la cuota se asigne a un agente no haya problemas de competencia (o más específicamente, de eficiencia asignativa), esto porque la cuota impone tal restricción de oferta al monopolista que éste no quiere extender dicha restricción más allá de lo que establece la cuota. 
FIGURA $N^{\circ}$ 1: $\quad$ MONOPOLISTA CON CUOTAS DE PESCA

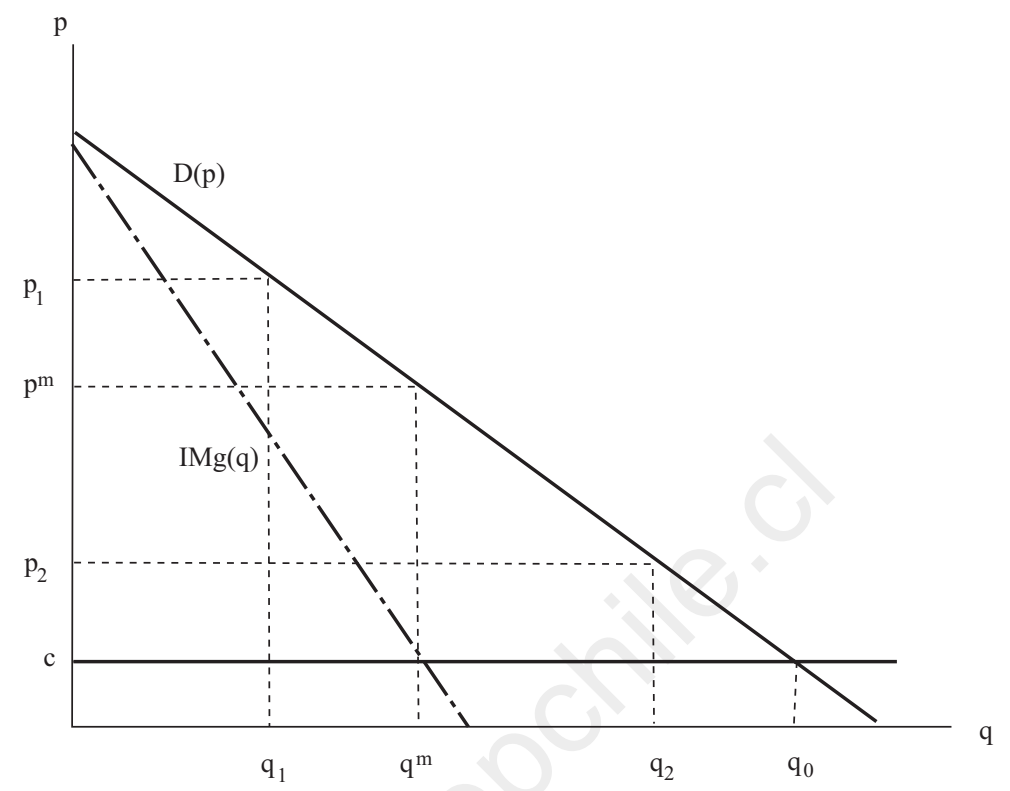

La Figura $\mathrm{N}^{\circ} 1$ puede ayudar a ilustrar esta posibilidad. La curva de demanda por pescado (congelado o fresco) en el mercado final viene dada por $\mathrm{D}(\mathrm{p})$, donde $\mathrm{p}$ es el precio por unidad y $\mathrm{q}$ es la cantidad vendida. La demanda inversa se denota por $\mathrm{P}(\mathrm{q})$. El costo para el monopolista de producir cada unidad es de c. Si el monopolista no enfrentase ninguna restricción a su producción, produciría en el punto donde su costo marginal, c, sea igual al ingreso marginal, $\operatorname{IMg}(q)$, lo que implica vender $\mathrm{q}^{\mathrm{m}}$ unidades a precio $\mathrm{p}^{\mathrm{m}}$. Cuando la cuota de pesca es igual o menor que $\mathrm{q}^{\mathrm{m}}$, el monopolista, y con ello cualquier otra estructura de mercado, pierde toda posibilidad de ejercer poder de mercado, ya que el precio final está dado exclusivamente por la curva de demanda. Por ejemplo, si la cuota global fijada por la autoridad es $\mathrm{q}_{1}$, el precio en el mercado final será el precio competitivo $\mathrm{p}_{1}$, independiente de si la cuota global está en manos de uno o varios agentes. Así, cuando la restricción que asegura la sustentabilidad del recurso es muy fuerte, es irrelevante desde un punto de vista de libre competencia (o, alternativamente, de uso socialmente eficiente de los recursos) asignar la totalidad de la cuota de pesca a un agente o varios agentes (ya que en este análisis los 
agentes son todos iguales y además con costos marginales constantes de explotación $)^{5}$.

La situación es distinta si la cuota global de pesca no es lo suficientemente restrictiva (i.e., mayor que $\mathrm{q}^{\mathrm{m}}$ en términos de la Figura $\mathrm{N}^{\circ} 1$ ), tal como aparentemente ocurre con la pesquería del bacalao de profundidad según PT\&F. En efecto, si la cuota global fijada por la autoridad es $\mathrm{q}_{2}$, el precio en el mercado final dependerá de la estructura de mercado.

Si la cuota global está en manos de un solo agente, este utilizará una parte de la cuota, $\mathrm{q}^{\mathrm{m}}$, logrando un precio final de $\mathrm{p}^{\mathrm{m}}$. A medida que el mercado se desconcentra y aumenta el número de agentes, la captura total se acercará a la cuota global y el precio en el mercado final a $\mathrm{p}_{2}$; a menos, eso sí, que los agentes puedan exitosamente implementar un acuerdo colusivo que replique la solución monopólica.

Quizá vale la pena detenerse un momento aquí y explicar que, a diferencia de otros mercados, un aumento en el número de agentes no necesariamente puede dificultar la colusión entre los agentes para una pesquería. Tal como se muestra formalmente en el correspondiente documento de trabajo (Montero 2011), si bien el factor de descuento crítico sobre el cual los agentes pueden sostener la solución monopólica en equilibrio (esto es, vender $\mathrm{q}^{\mathrm{m}}$ a precio $\mathrm{p}^{\mathrm{m}}$ ) sube con el número de agentes, este factor está acotado a un techo que entre otras cosas depende de la razón entre la cuota global entregada por la autoridad y la cantidad monopólica.

Este techo puede ser bastante menor que la unidad, lo que haría menos relevante la estructura de mercado al momento de sostener colusión. Por ejemplo, si la solución monopólica es utilizar solamente el $50 \%$ de la cuota - como ocurrió en varios períodos con la pesquería del bacalao de profundidad según documentado por PT\&F-y las utilidades de las firmas en el equilibrio competitivo son cercanas a cero, el techo para el factor de descuento crítico es 0,5. En cambio, en otros modelos de competencia oligopólica ( $v$. gr., Cournot, Bertrand con o sin diferenciación de productos, etc.) el factor de descuento crítico sube rápida y

${ }^{5}$ Nótese que en ausencia de cuotas, es decir, bajo un régimen de libre entrada, las firmas extraerían $\mathrm{q}_{0}$ este período, donde el precio es igual al costo medio. Esta sobre-explotación se vería reflejada en el próximo período con una mucho menor disponibilidad de peces. 
monotónicamente hasta alcanzar la unidad ${ }^{6}$. La pesquería es especial, producto de la restricción en la oferta tanto individual como global que imponen las cuotas, lo que finalmente limita los incentivos al desvío.

Continuando con el argumento anterior, si en el mercado uno observa la total utilización de la cuota asignada, cualquier aumento en el número de agentes no conduce a ganancias de eficiencia ya que la cuota seguirá siendo utilizada en su totalidad. Nótese además que a medida que la demanda por productos del mar crece pero no así la masa de peces, o más específicamente la tasa sustentable de captura, el interés que podría tener un monopolista o un grupo de empresas en utilizar sólo una fracción de su cuota disminuye. Los precios de harina de pescado, por ejemplo, se han más que triplicado en los últimos diez años, haciendo mucho menos probable observar agentes que usen, por voluntad propia, sólo una fracción de la cuota asignada.

Si bien PT\&F plantean la posibilidad de que en la pesquería del bacalao de profundidad las firmas hayan sistemáticamente capturado por debajo de las cuotas asignadas como resultado de un equilibrio no cooperativo del tipo Cournot, me gustaría insistir un poco en este argumento preguntando: ¿qué tan estable es este equilibrio en el tiempo? Esta pregunta está directamente relacionada con los incentivos que podría tener una firma existente en el mercado, que sólo utiliza una fracción de su cuota, para vender la fracción no utilizada, o al menos una parte de ella, a un potencial entrante (estoy pensando en un entrante con los mismos costos de extracción que los existentes para concentrarnos en temas puramente estratégicos; además estoy asumiendo que posterior a la entrada las $\mathrm{n}+1$ firmas continúen compitiendo no-cooperativamente a la Cournot). La respuesta es muy simple: tiene todos los incentivos para hacerlo ya que de esa forma la firma puede creíblemente implementar su solución Stackelberg, es decir, "mover estratégicamente primero que el resto" y lograr con esto una producción mayor.

Para explicar este resultado, imaginemos la siguiente situación. Las $\mathrm{n}$ firmas compitiendo a la Cournot llegan, en equilibrio, a una pesca agregada $\mathrm{q}^{\text {nc }}$ menor que la cuota global $\mathrm{q}^{\mathrm{TAC}}$ (TAC viene de total allowable catch) pero no mucho menor para simplificar el argumento (recuerde que cada una de estas $\mathrm{n}$ firmas recibió una cuota individual

${ }^{6}$ Por ejemplo, en un modelo Bertrand con productos homogéneos y sin restricciones de capacidad el factor de descuento crítico, en función del número de firmas, viene dado por $\delta=1-1 / \mathrm{n}$, donde $\mathrm{n}$ es el número de firmas. 
de $\left.\mathrm{q}^{\mathrm{TAC}} / \mathrm{n}\right)$. Suponga ahora que una de las $\mathrm{n}$ firmas, digamos la firma 1 , se "adelanta al resto y mueve primero" en el sentido estratégico de Stackelberg, es decir anunciando su producción. Dada la sustituibilidad estratégica de las cantidades, es decir que si yo produzco más el otro produce menos, si la firma 1 aumenta su producción por encima de $\mathrm{q}^{\text {nc}} / \mathrm{n}$, la reacción de equilibrio de cada una de las restantes $\mathrm{n}-1$ firmas será producir algo menos que $\mathrm{q}^{\mathrm{nc}} / \mathrm{n}^{7}$ Como estamos suponiendo que $\mathrm{q}^{\text {nc }}$ no es mucho menor que $\mathrm{q}^{\mathrm{TAC}}$, es fácil imaginar que la cantidad Stackelberg para la firma 1 es vender toda su cuota, i.e., $\mathrm{q}^{\mathrm{nc}} / \mathrm{n}$. Pero en el juego simultáneo Cournot, la firma 1 no tiene forma de anunciar creíblemente que venderá toda su cuota. ¿Qué podría hacer la firma 1 entonces? Vender una fracción de su cuota a un entrante tal que en el equilibrio Cournot de $\mathrm{n}+1$ firmas, la firma 1 y la firma entrante puedan creíblemente, es decir, en equilibrio, vender toda la cuota $\mathrm{q}^{\mathrm{nc}} / \mathrm{n}$ e implementar así la solución Stackelberg de la firma 1. Conocer el precio exacto a que la firma 1 vende parte de sus cuotas a la firma entrante es inmaterial, basta saber que es una transacción mutuamente beneficiosa, ya que las utilidades son mayores. La firma entrante vende "credibilidad" a la firma 1 para que ésta pueda aumentar su producción.

Nótese que este argumento no es muy distinto al de Salant et al. (1983) que dice que cuando hay más de dos empresas en un mercado Cournot (con costos constantes y sin restricciones de capacidad), no existen incentivos para la fusión entre dos empresas, esto porque las utilidades de la empresa fusionada son menores que la suma de las utilidades de las dos empresas antes de la fusión. Esto es equivalente a decir que en un mercado Cournot, una empresa quisiera "dividirse en dos" ya que las utilidades de estas dos empresas en el equilibrio Cournot son mayores que las utilidades de la empresa original. Esto último es exactamente lo que estoy diciendo más arriba. Vender cuotas a un tercero es una forma directa y relativamente fácil de "dividirse en dos"; no así partir una empresa en dos.

Naturalmente la argumentación anterior no termina con la firma 1. La firma 2 también tendrá los mismos incentivos que la firma 1 para vender parte de su cuota a un entrante para implementar su solución Stackelberg. Lo que está pasando es que cada firma quiere "viajar gratis" (free ride) sobre los esfuerzos de reducción de producción del

${ }^{7}$ La sustituibilidad estratégica se obtiene directamente de la condición de primer orden para cualquiera de las n-1. Véase Montero (2011). 
resto. Estos incentivos desaparecen sólo cuando el total de la cuota está en manos de un agente o cuando hay un solo agente estratégico. Como todas las firmas quieren hacer lo mismo esto termina por destruir el equilibrio Cournot original y lleva a una utilización total de la cuota global ${ }^{8}$. Según esta lógica lo único que podría sostener una producción por debajo de la cuota asignada sería un acuerdo colusivo. Hay entonces aquí un resultado muy importante que vale la pena reforzar: en principio no habría razones estratégicas para no utilizar la totalidad de las cuotas a menos que las firmas actuaran de forma cooperativa (i.e., de forma colusiva) o que hubiese un solo agente estratégico con una parte importante de la cuota global.

\subsection{Economías de escala}

Hasta ahora habíamos supuesto una función de producción para la industria con retornos constantes a escala. Pero tal como reconocen PT\&F en su trabajo, la industria pesquera exhibe importantes economías de escala, lo que se traduce en que, en equilibrio, habrá un número relativamente menor de operadores. Según PT\&F hay economías de escala en las distintas fases del negocio, desde la captura, pasando por el procesamiento hasta la inversión en comercialización de los productos en los mercados internacionales.

Desde un punto de vista de la libre competencia y para el caso hipotético en que la cuota global no sea utilizada en su totalidad en equilibrio (Cournot), la existencia de economías de escala introduce un tradeoff entre eficiencia productiva y eficiencia asignativa. En este caso la autoridad puede estar dispuesta a sacrificar eficiencia asignativa, es decir, que no se capture la cuota global y se permita que los precios se alejen del nivel competitivo $\mathrm{P}\left(\mathrm{q}^{\mathrm{TAC}}\right)$ en pos de ganar eficiencia productiva.

En Montero (2011) se muestra formalmente que si los costos fijos de una firma - los responsables de las economías de escala - son mayores que un cierto nivel mínimo, es socialmente (segundo-mejor) óptimo que no se capture la totalidad de la cuota asignada (dada la com-

${ }^{8}$ Aquí hay un paralelo con el resultado de Allaz y Vila (1993), quienes muestran que en un mercado Cournot, donde las empresas tienen la posibilidad de implementar su solución Stackelberg creíblemente vía la venta de contratos forward, se termina con un equilibrio donde todas las firmas venden contratos forward y el mercado se hace más competitivo. Éste es un resultado particularmente relevante en los mercados eléctricos. 
petencia oligopólica entre empresas) $)^{9}$. A diferencia de lo que ocurre en un mercado convencional, este nivel mínimo es estrictamente positivo en una pesquería porque la restricción biológica $\mathrm{q}^{\mathrm{TAC}}$ introduce una suerte de distorsión - crea rentas de escasez- alejando el precio competitivo $\mathrm{P}\left(\mathrm{q}^{\mathrm{TAC}}\right)$ del costo marginal $\mathrm{c}$. En última instancia, esto implica que aun si uno observa que la cuota asignada no esté siendo utilizada en su totalidad, esto no significa que la tensión entre eficiencia productiva y eficiencia asignativa no esté bien resuelta por el mercado.

\subsection{Mercados externos e internos}

Hasta ahora, este análisis de competencia se ha realizado bajo el supuesto implícito que la totalidad de la producción y consumo se realiza en una misma jurisdicción, a saber, en el territorio nacional. El análisis de competencia obviamente cambia cuando, por ejemplo, parte importante del consumo ocurre en territorio extranjero. Si la totalidad del consumo ocurre fuera de nuestras fronteras, tal como según PT\&F sería el caso para la pesquería del bacalao de profundidad, la autoridad de competencia debiera enfocarse casi exclusivamente en promover la eficiencia productiva (algo que tocaré más en detalle en la próxima sección cuando introduzca heterogeneidad de firmas, pero por ahora mantengamos el supuesto de firmas simétricas). PT\&F dicen, en efecto, que las empresas nacionales son capaces de afectar el mercado internacional. Pero eso no debiera preocupar a las autoridades de competencia nacionales, todo lo contrario.

Las firmas que operan en las pesquerías nacionales que nos ocupan reparten su producción entre el mercado nacional y el internacional; es el caso del aceite y la harina de pescado, y las conservas. El mercado nacional de los congelados, en cambio, es marginal. Al existir ambos mercados, el externo y el interno, el análisis de competencia para las autoridades locales se torna un poco más complejo ya que se requiere revisar distintas posibilidades. La primera posibilidad es que ambos mercados estén perfectamente integrados si los costos de transporte son relativamente menores. Si éste fuera el caso, la variable a considerar es el tamaño relativo de los mercados. Si el mercado nacional es bastante

${ }^{9}$ Naturalmente nunca va a ser óptimo dejar cuota sin utilizar si las empresas se comportan como si fueran tomadoras de precio. 
menor que el internacional, la autoridad de competencia debiera, al igual que en la pesquería del bacalao de profundidad, enfocarse exclusivamente en problemas de eficiencia productiva, si es que los hay. Esto porque cualquier pérdida de eficiencia asignativa en el mercado nacional (i.e., producto de precios más altos que los competitivos) está más que compensada por las ganancias de las empresas nacionales a expensas de consumidores internacionales que son muchos más que los locales ${ }^{10}$. A medida que el mercado interno aumenta de tamaño, sin embargo, cobra importancia la discusión de las dos secciones anteriores (Secciones 2.3 y 2.4).

La segunda posibilidad es que los costos de transporte sean lo suficientemente importantes como para producir una segmentación de mercados (es el equivalente a la total congestión de una línea de transmisión que conecta dos mercados eléctricos). Esta segmentación no implica que los precios en ambos mercados se muevan en direcciones distintas sino más bien que los precios se distancian, pero no más allá del costo de transporte, esto es

$$
\mathrm{p}^{\mathrm{i}}-\mathrm{t} \leq \mathrm{p}^{\mathrm{n}} \leq \mathrm{p}^{\mathrm{i}}+\mathrm{t}
$$

donde $t$ es el costo de transporte, ya sea para importar desde o exportar hacia el mercado internacional, $\mathrm{p}^{\mathrm{n}}$ es el precio de equilibrio en el mercado nacional y $\mathrm{p}^{\mathrm{i}}$ es el precio de equilibrio en el mercado internacional. Así, el precio neto de transporte que recibe un productor nacional por su producción en el mercado internacional es $\mathrm{p}^{\mathrm{i}}-\mathrm{t}$. Por otro lado, un consumidor nacional que importa desde el exterior debe pagar $\mathrm{p}^{\mathrm{i}}+\mathrm{t}$. Ahora bien, el precio en el mercado nacional no puede ser mayor que $\mathrm{p}^{\mathrm{i}}$ $+\mathrm{t}$ porque, caso contrario, los consumidores preferirían importar todo su consumo. El precio en el mercado nacional tampoco puede caer por debajo de $\mathrm{p}^{\mathrm{i}}-\mathrm{t}$, porque entonces ningún productor local vendería en el mercado nacional.

Suponiendo que el precio $\mathrm{p}^{\mathrm{i}}$ está dado (i.e., exógeno para los productores nacionales), ¿qué debiera esperar uno respecto de $\mathrm{p}^{\mathrm{n}}$ ? Si la producción nacional estuviese en manos de un agente uno esperaría

${ }^{10}$ Notar además que al estar los mercados perfectamente integrados no hay prácticamente instrumento que la autoridad pueda usar para aumentar la venta en el mercado nacional sin que esto sea arbitrado por consumidores internacionales. 
observar precios cercanos a $\mathrm{p}^{\mathrm{i}}+\mathrm{t},{ }^{11}$ los que debieran caer al aumentar el número de productores locales ${ }^{12}$. Y aquí caemos en exactamente el mismo tipo de análisis de competencia que se aplica a cualquier mercado convencional donde la concentración de mercado adquiere especial relevancia; pero de una forma especial porque lo que al final importa no es el tamaño de cada actor (por ejemplo medido como la fracción de la cuota global) sino el número de actores.

Tal como se muestra formalmente en el Anexo, todas las compañías venderán lo mismo en el mercado interno, independiente de su costo de extracción y, más importante aun, de su cuota individual (a menos que esta última sea bastante menor, en cuyo caso venderían el total de su cuota individual en el mercado local). Esto porque lo relevante para estas compañías al momento de decidir cuánto vender en el mercado interno no es el costo de extracción sino el costo de oportunidad de dejar de vender en el exterior $\left(p^{i}-t\right)$. Y ese costo de oportunidad es el mismo para todas las firmas independientemente de la cuota individual y del costo de extracción.

En el Anexo se muestra formalmente que la venta en equilibrio (Cournot) de cada una de las compañías en el mercado local viene dada por la siguiente expresión

$$
\mathrm{q}^{\mathrm{n} / \mathrm{n}}=\left[\mathrm{P}\left(\mathrm{q}^{\mathrm{n}}\right)-\left(\mathrm{p}^{\mathrm{i}}-\mathrm{t}\right)\right] / \mathrm{P}^{\prime}\left(\mathrm{q}^{\mathrm{n}}\right)
$$

donde $\mathrm{q}^{\mathrm{n}}$ es la venta agregada en el mercado nacional, $\mathrm{n}$ es el número de firmas, y $\mathrm{P}^{\prime}\left(\mathrm{q}^{\mathrm{n}}\right)$ es la derivada de la curva de demanda. De la expresión (1) se desprende que la venta local para una empresa $\mathrm{j}$ cualquiera es efectivamente independiente de la cuota individual $\mathrm{q}_{\mathrm{j}}^{\mathrm{TAC}} \mathrm{y}$ del costo de extracción $c_{j}$ (ver Anexo). Esta simple pero poderosa observación nos permite contar con un test muy simple de competencia que no re-

${ }^{11}$ El monopolista puede fijar un precio menor si la solución a

$$
\operatorname{Max}_{q} P(q) q+\left(p^{i}-t\right)\left(q^{T A C}-q\right)-c q^{T A C}
$$

resulta en un precio menor que $\mathrm{p}^{\mathrm{i}}+\mathrm{t}$. Recuerde que $\mathrm{P}(\mathrm{q})$ es la demanda nacional, q es la venta nacional y q q $^{\text {TAC }}$ es la cuota de monopolista que utiliza por completo, ya que $\mathrm{p}^{\mathrm{i}}-\mathrm{t}-\mathrm{c}>0$.

${ }^{12}$ Como consecuencia del aumento de las ventas locales a expensas de las internacionales (la venta total se mantiene constante ya que siempre se utiliza el total de la cuota). 
quiere de datos de precios ni costos, los cuales son siempre difíciles de obtener. Por ejemplo, una compañía que tenga asignada una cuota individual menor que $\mathrm{q}^{\mathrm{n}} / \mathrm{n}$ debiera vender el total de su cuota en el mercado local a menos que el margen $\mathrm{P}\left(\mathrm{q}^{\mathrm{n}}\right)-\left(\mathrm{p}^{\mathrm{i}}-\mathrm{t}\right)$ sea tan pequeño que resulte indiferente repartir su producción entre el mercado interno y el externo. En otras palabras, si se observan compañías con pequeñas cuotas, como Lota Protein por ejemplo (para ser más preciso con cuotas individuales por debajo de $\mathrm{q}^{\mathrm{n}} / \mathrm{n}$ ), que exportan parte importante de su producción, esto sería evidencia de un mercado nacional competitivo. Porque si no lo fuera, es decir, si el margen $P\left(q^{n}\right)-\left(p^{i}-t\right)$ fuera importante, dicha compañía debiera vender todo en el mercado local. Y con mayor razón si este alto margen es producto de una colusión en el mercado local.

Pero si uno insiste en que el mercado nacional exhibe importantes márgenes como resultado de una competencia oligopólica (i.e., Cournot) de pocos actores, el análisis al final de la sección 2.3 sigue siendo igualmente válido aquí. Cualquier firma quisiera implementar su solución Stackelberg en el mercado local, es decir, "mover estratégicamente primero" para apropiarse en forma creíble de un mayor porcentaje de las rentas oligopólicas que se generan en el mercado local. Y la forma de hacerlo es precisamente vendiendo parte de las cuotas a un tercero - parte de las cuotas destinadas a satisfacer el mercado externo- que hoy no está en el mercado local o está con una cuota tan menor que vende su totalidad en el mercado local.

\subsection{Heterogeneidad de firmas y transferibilidad de cuotas}

Hasta ahora hemos supuesto homogeneidad de firmas. Claramente éste es un supuesto que se aleja de la realidad tal como reconocen PT\&F en su trabajo. Al existir heterogeneidad de firmas, debido al uso de distintas tecnologías de producción, tiempo de entrada al mercado, tamaño, etc., es importante que las cuotas individuales estén en manos de aquellos que más las valoran, es decir, de aquellos con menores costos de explotación. En caso contrario se estaría violando la condición de eficiencia productiva. En principio, la forma de cumplir con esta condición es permitir la libre transferibilidad de las cuotas individuales de pesca, esto es, permitir que fluyan desde aquellos que menos las valoran hacia aquellos que más las valoran. 
Si las cuotas son efectivamente transables uno podría recurrir al teorema de Coase y afirmar que la eficiencia productiva siempre se consigue independientemente de la asignación inicial de las cuotas. En términos generales el teorema de Coase plantea que en ausencia de costos de transacción y de asimetrías de información los agentes van a transar cuotas hasta agotar todas las transacciones que sean socialmente beneficiosas; en otras palabras, hasta cumplir con la eficiencia productiva (Coase, 1960). Es un poco ingenuo suponer que el teorema de Coase siempre se cumple en la práctica casi por construcción.

Hay al menos dos elementos — costos de transacción y poder de mercado- que pueden impedir su cumplimiento, tal como lo documenta Tietenberg (2006), aunque él pone particular atención en las transacciones de cuotas/permisos de contaminación ${ }^{13}$.

Los costos de transacción pueden tener distintos orígenes. Uno es que las cuotas de pesca estén definidas de una forma que dificulten su transferibilidad. A diferencia de lo que ocurre en la mayoría de las pesquerías de Islandia y Nueva Zelanda, la cuotas individuales en las pesquerías chilenas, según la Ley 19.713 del 2001, no son asignadas directamente a las empresas sino que a sus embarcaciones, lo que implica que cualquier transacción de cuotas pasa necesariamente por la transacción de embarcaciones completas. Esto sin duda hace más costosa la transferibilidad por varias razones. En primer lugar, impone un tamaño mínimo a la transacción por la indivisibilidad que significa transar una embarcación completa. En segundo lugar, intensifica problemas de información asimétrica porque en vez de transar un bien absolutamente homogéneo, como es un permiso para pescar/emitir una tonelada en un período determinado, la transacción incorpora una embarcación cuyas características pueden ser difíciles de observar por una de las partes. $\mathrm{Y}$ en tercer lugar impide transacciones de menor duración, tales como arriendo de cuotas por un período de un año o menos (es más difícil arrendar embarcaciones completas por un año). Esto puede ser potencialmente importante, sobre todo cuando las cuotas son asignadas a perpetuidad, como ocurre mayoritariamente en Nueva Zelanda e Islandia.

${ }^{13}$ Stavins (1995) y Montero (1998) también estudian costos de transacción en mercados de permisos de contaminación. Estos autores explican que gran parte de los costos de transacción, cuando existen, se debe a incertidumbre regulatoria respecto de la aprobación de las transacciones. Esto es algo que no ocurre en mercados de cuotas de pesca. 
Newell et al. (2005) muestran para las pesquerías de Nueva Zelanda que al poco tiempo de implementación del sistema de cuotas individuales transferibles en 1986, los volúmenes de transacciones de arriendos (típicamente de un año) sobrepasaron los volúmenes de ventas llegando el año 2000 a ser diez veces más altos. Más interesante aún son los volúmenes de las transacciones como porcentaje del total de cuota asignada. En el caso de las ventas, los volúmenes promedio han caído constantemente desde un máximo de $23 \%$ en 1986 hasta $5 \%$ en 2000. La historia es totalmente distinta en los arriendos, cuyos volúmenes promedio han subido constantemente desde un mínimo de $9 \%$ en 1986 hasta $44 \%$ en el 2000.

La experiencia en Chile con arriendo de cuotas no es muy distinta a lo que describen Newell et al. (2005). En aquellas pesquerías donde las cuotas individuales se pueden transferir en forma autónoma tal como en Nueva Zelanda — bacalao de profundidad, orange roughy, langostino colorado y langostino amarillo-, se ha observado un mercado activo de contratos de arriendo. Para la pesquería del langostino colorado, por ejemplo, los contratos de arriendo han fluctuado entre $20-30 \%$ de la cuota global de cada año. En el caso de la pesquería del bacalao de profundidad, este porcentaje fluctuó entre 20-35\% durante 1992-96 para caer a $5 \%$ o menos en años posteriores (Peña-Torres, 2002).

Los costos de transacción también pueden tener su origen en un reducido número de agentes, lo que hace más difícil la creación de un mercado líquido para la transacción de cuotas; algo que también es documentado por Newell et al. (2005). Estos mismos autores muestran que esto es menos importante si se permiten transacciones de corta duración (i.e., arriendos).

El teorema de Coase y con ello la eficiencia productiva también pueden fallar cuando existen agentes con una asignación de cuotas suficientemente alta como para ejercer poder de mercado. Hahn (1984) fue el primero en mostrar cómo un agente de tamaño importante podría ejercer poder de mercado en un mercado de derechos de propiedad cuando el resto de los derechos está en manos de muchos pequeños agentes. Aunque la motivación central de Hahn (1984) fueron los permisos de contaminación, sus resultados igualmente se aplican a cuotas de pesca (y a derechos de agua si se quiere). Antes de discutir el resultado de Hahn es importante aclarar que hay dos casos a considerar. El primero es aquel donde el agente estratégico (o de tamaño importante) 
ejerce poder de mercado en ambos mercados, en el mercado del producto final (v.gr., congelados) vía un uso parcial de su cuota, y en el mercado de compra y venta de cuotas vía una transferencia menor de cuotas que lo que hubiese ocurrido si todos los agentes fueran tomadores de precio. El segundo caso es aquel donde el agente estratégico sólo ejerce poder de mercado en el mercado de cuotas, es decir, usa toda su cuota pero restringe la transferencia de cuotas a terceros con el objeto de levantar el precio de las mismas. Como este último es el caso más relevante para nosotros, tal como veremos en la próxima sección, lo explicamos a continuación ${ }^{14}$.

La idea de Hahn se puede explicar fácilmente con la ayuda de la Figura $\mathrm{N}^{\circ} 2$. Sobre el eje horizontal se colocan simultáneamente las cuotas/ventas de una empresa grande o estratégica $\left(\mathrm{q}_{\mathrm{s}}\right)$, medidas desde izquierda a derecha, y las cuotas/ventas de un grupo de empresas pequeñas al que llamamos el borde competitivo $\left(\mathrm{q}_{\mathrm{b}}\right)$, medidas desde derecha a izquierda. La distancia sobre el eje horizontal entre ambos ejes verticales es exactamente $\mathrm{Q}$, la cuota global, que antes denotamos por $\mathrm{q}^{\mathrm{TAC}}$. Las demandas por cuotas, o la disposición a pagar por las mismas, vienen dadas por $D_{s}(p)$ y $D_{b}(p)$ respectivamente ${ }^{15}$.

Suponga que inicialmente la empresa estratégica recibe una cuota individual de $\mathrm{Q}_{\mathrm{s}} \mathrm{y}$ el borde competitivo de $\mathrm{Q}_{\mathrm{b}}=\mathrm{Q}-\mathrm{Q}_{\mathrm{s}}$. Según el teorema de Coase estos dos grupos de empresas, la estratégica y el borde competitivo, debieran transar cuotas hasta que la disposición a pagar por una cuota adicional de cada grupo de empresas se iguale. Esto se alcanza cuando la empresa estratégica vende $\mathrm{Q}_{\mathrm{s}}-\mathrm{q}_{\mathrm{s}}^{*}$ cuotas al borde competitivo a precio $\mathrm{p}^{*}$. Cuando la empresa es grande, sin embargo, ésta restringirá su venta hasta el punto en que su ingreso marginal (IMg) por vender una unidad más sea igual a su costo de oportunidad. Así, la empresa estratégica sólo venderá $\mathrm{Q}_{\mathrm{s}}-\mathrm{q}_{\mathrm{s}}^{\mathrm{m}}$ cuotas a precio $\mathrm{p}^{\mathrm{m}}$, generando una pérdida de eficiencia productiva igual al triángulo achurado.

Suponga ahora el caso en que inicialmente la empresa estratégica recibe una cuota igual a $q_{s}^{*}$ y el borde competitivo igual a $q_{b}^{*}=Q-q_{s}^{*}$. En este caso no hay problemas de poder de mercado. En otras palabras,

${ }^{14}$ Un tratamiento más reciente y completo sobre poder de mercado en mercados de permisos de contaminación, incluyendo el ejercicio doble de poder de mercado, se puede encontrar en Montero (2009).

${ }^{15} \mathrm{Al}$ suponer que estas curvas de demanda tienen pendientes negativas estamos implícitamente suponiendo que las firmas están operando en una zona de retornos decrecientes a escala. 


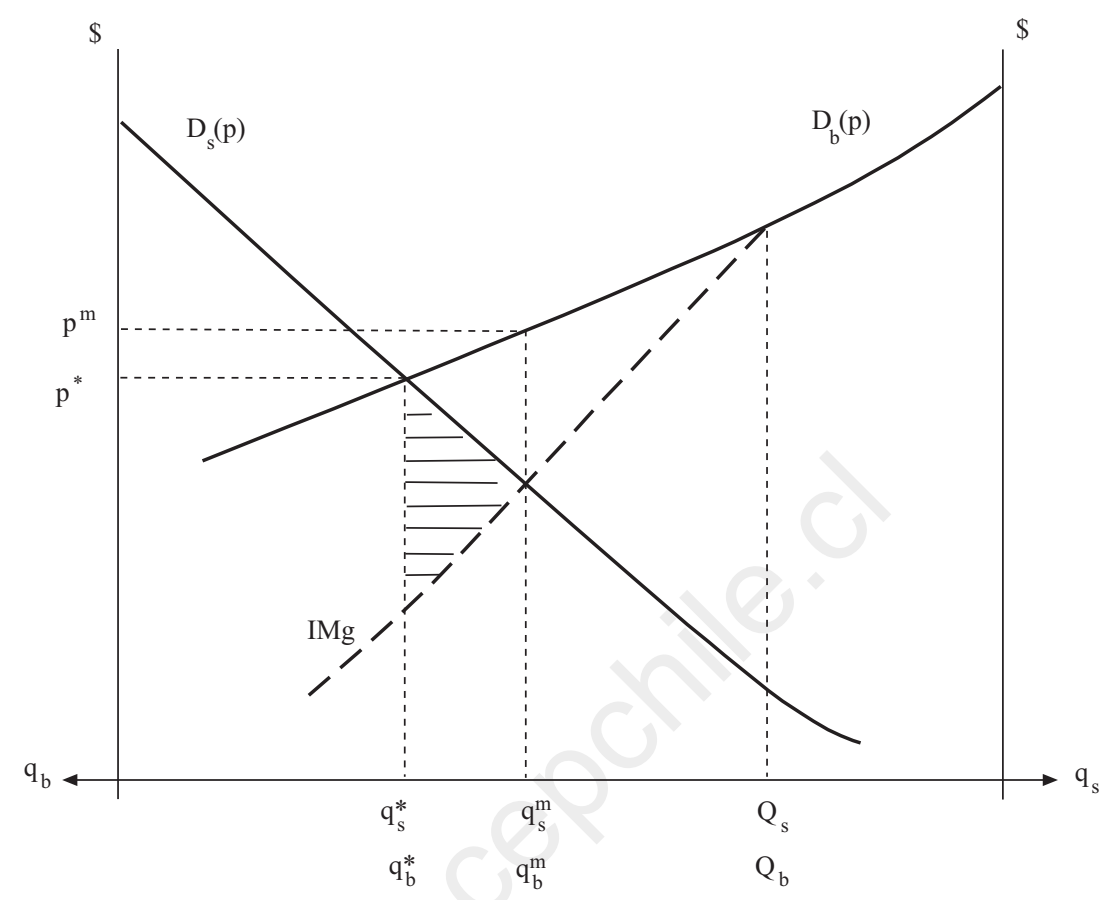

el problema de eficiencia productiva desaparece cuando la asignación inicial, al menos para la o las empresas estratégicas, o de gran tamaño, es igual a la asignación socialmente eficiente.

Adicionalmente, hay un problema de inconsistencia temporal en el modelo de Hahn (1984) que hace aún más improbable el ejercicio de poder de mercado ${ }^{16}$. El modelo de Hahn supone que el agente estratégico realiza una sola venta y ya. ¿Qué pasa si terminada la primera venta, que resulta en cuotas de $\mathrm{q}_{\mathrm{s}}^{\mathrm{m}}$ y $\mathrm{q}_{\mathrm{b}}^{\mathrm{m}}$ para el agente estratégico y el borde competitivo respectivamente, permitimos al agente hacer una segunda venta? Obviamente al agente estratégico le gustaría hacer una segunda venta ya que hay una brecha entre lo que está dispuesto a pagar el borde competitivo por una cuota adicional y lo que él o ella está dispuesto/a a recibir. La mera oportunidad de volver al mercado a vender período tras período erosiona el poder de mercado del agente estratégico de la misma forma que un monopolista de un bien durable pierde su poder de

${ }^{16}$ Para una discusión completa véase Liski y Montero (2011) 
mercado cuando tiene la oportunidad de ir al mercado en forma frecuente (Coase, 1972) ${ }^{17}$. Al fin y al cabo las cuotas son bienes durables. Una forma de resolver este problema de bien durable para el agente estratégico es con el arriendo de cuotas en vez de su venta. Pero esta forma de transacción, tal como se explicaba más arriba, no se ha observado en los mercados de cuota en la zona centro-sur ${ }^{18}$.

Hemos visto que en presencia de costos de transacción y de poder de mercado el teorema de Coase no es suficiente para asegurar eficiencia productiva para cualquier asignación inicial de cuotas individuales. Aun si uno está seguro que las cuotas están en manos de aquellos que más las valoran, es igualmente útil preguntarse qué se podría hacer en caso de ocurrir lo contrario. No es inmediatamente obvio ya que la autoridad rara vez tiene toda la información para realizar una reasignación de cuotas que mejore el bienestar.

Por ejemplo, trasladar cuotas desde un actor de mayor tamaño (i.e., con más cuota) a uno de menor tamaño puede resultar en pérdidas de bienestar si se desaprovechan economías de escala o si se pasa de no tener poder de mercado a tener poder monopsónico. La autoridad quisiera utilizar un mecanismo de revelación honesta de información por parte de las firmas para realizar dicha tarea de reasignación, en caso que lo estime necesario. En principio, un mecanismo de subasta podría jugar ese rol. Volveremos a este punto en la sección 4.

\subsection{Inversiones irreversibles}

Hay un último elemento, muy relacionado con la heterogeneidad, que se discutió en la sección anterior, que es importante tener en cuenta al momento de analizar la competencia en pesquerías. Al igual que en muchos otros mercados, la actividad pesquera requiere de inversiones

${ }^{17}$ En otros mercados de derechos de propiedad (v.gr., derechos de agua, permisos de contaminación) el problema de bien durable no es tan severo como en pesca — cuando se usa toda la cuota - ya que los agentes también pueden estar compitiendo imperfectamente en el mercado del bien final ( $v . g r$, generación eléctrica). Evitar caída en los precios del bien final es el compromiso que necesita el agente estratégico para no seguir vendiendo cuotas en el mercado de cuotas. Es equivalente a tener un costo marginal creciente como en Kahn (1986).

${ }^{18}$ Ha habido algunas experiencias, muy marginales, de "arrendamiento" en la forma de asociación de armadores. Esta forma de arrendamiento es claramente distinta a la que hacía mención más arriba. 
de largo plazo con un componente de irreversibilidad. Esto significa que una parte de estas inversiones no puede ser recuperada en el mercado si la empresa decide, por ejemplo, retirarse del negocio; en otras palabras, hay activos específicos a una empresa que no pueden ser transferidos a otra empresa. ¿Qué tan importantes son estas irreversibilidades, también conocidas como inversiones hundidas? Ésa es una pregunta empírica y que varía según la pesquería. Peña-Torres y Fernández (PT\&F) comentan para la pesquería del bacalao de profundidad, por ejemplo, que las empresas tienen que invertir importantes sumas en desarrollar "redes de comercialización hacia y dentro de los mercados de exportación". PT\&F continúan diciendo que la "construcción de confianza y reputación es un requisito frecuente en la comercialización de productos del mar, dada la existencia de asimetrías de información relacionadas con la perecibilidad y calidad heterogénea del producto final (sea en términos de su frescura o técnica de congelado)". Éste claramente es un activo específico a la firma, mucho más que embarcaciones y centros de procesamiento. Posiblemente para otro tipo de productos, como la harina y aceite de pescado, la construcción de "confianza y reputación" sea menos relevante dada su "comoditización".

Tal como lo reconocen PT\&F en su trabajo, la presencia de irreversibilidades significa que la disposición a pagar por una cuota de pesca de una firma existente - que ya hundió una parte de sus inversiones - es mayor que la disposición a pagar de una firma que quiere entrar al mercado. ¿Constituye esta heterogeneidad una barrera para alcanzar eficiencia productiva y/o asignativa? La pregunta es pertinente porque, por ejemplo, PT\&F explican que debido a esta heterogeneidad y al uso parcial de la cuota global la pesquería del bacalao de profundidad ha visto frustrada, ya en dos oportunidades, la entrada de nuevos actores (volveremos a este asunto en más detalle en la sección 4 cuando veamos subastas).

Cuando la cuota global está siendo utilizada en su totalidad la respuesta es inmediata y negativa. La heterogeneidad que generan estas irreversibilidades es igual, desde un punto de vista de competencia, a cualquiera otra; es una ventaja de costo que no constituye una barrera a la entrada. ¿Para qué hundir nuevamente una inversión que no significa un ahorro en el resto de los costos? Cuando la cuota global no es utilizada en su totalidad, tal como explican PT\&F para la pesquería del bacalao de profundidad, uno pudiera pensar que los problemas de eficiencia 
asignativa se incrementan por causa de estas irreversibilidades. Pero la verdad es que nada del análisis en la sección 2.3 cambia. Sigue siendo igualmente válido el que una empresa existente quiera implementar su solución Stackelberg vendiendo parte o la totalidad de la fracción de la cuota no utilizada a un entrante.

\section{3 ¿Qué dicen los datos?}

Con el marco teórico de la sección anterior podemos ahora ir a los datos y testear que efectivamente hay problemas de competencia en las pesquerías que nos ocupan.

\section{1. ¿Se han usado todas las cuotas asignadas?}

Como primer ejercicio empírico veamos el uso de las cuotas de pesca. En la Tabla $N^{\circ} 1$ se muestra un resumen con las cuotas (industriales) globales de pesca de distintas pesquerías y en distintas regiones del país y la captura respectiva. En la mayoría de los casos, la cuota se ha utilizado en su totalidad, e incluso por encima de la cuota en algunos otros. Esto eliminaría cualquier sospecha de manipulación en la utilización de las cuotas asignadas con el objeto de levantar precios de productos finales por encima de los competitivos. Hay algunos casos, sin embargo, que merecen atención ya que se ve una reducción importante en la utilización de la cuota como, por ejemplo, el jurel III-X en los años 2008 y 2009, la anchoveta XV-II entre 2006 y 2009, y la anchoveta III-IV en todos los años. Lo que explica esta caída importante en la utilización de la cuota es la menor disponibilidad del recurso. Hay antecedentes que explican que éste es el caso ${ }^{19}$. Además sería extraño que no fuese así ya que la cuota del jurel fue utilizada en su totalidad antes del 2007 y la anchoveta XV-II lo mismo antes del 2006 cuando los precios, de la harina de pescado por ejemplo, eran más bajos. Hay que sumar a esto que tampoco hubo cambios importantes en la estructura de mercado de la industria. Por otra parte, la caída por debajo de la cuota para la anchoveta III-IV no requiere de mayor discusión ya que corresponde a una fracción muy menor del total.

${ }^{19}$ Conversación con personal de la industria pesquera, Rodrigo Sarquis entre otros, en abril de 2010. 
TABLA N ${ }^{\circ}$ 1: $\quad$ LÍMITES MÁXIMOS DE CAPTURA (LMC) Y CAPTURA INDUSTRIAL 2002-2009 (en toneladas)

\begin{tabular}{|c|c|c|c|}
\hline 2009 & LMC industrial & Captura industrial & Dif. (\%) \\
\hline Jurel XV-II & 126.350 & 134.087 & 6,1 \\
\hline Jurel III-X & 1.135 .097 & 655.758 & $-42,2$ \\
\hline Anchoveta XV-II & 1.094 .986 & 367.122 & $-66,5$ \\
\hline Anchoveta III-IV & 50.410 & 6.663 & $-86,8$ \\
\hline Anchoveta V-X & 181.357 & 171.328 & $-5,5$ \\
\hline Sardina común V-X & 259.325 & 251.245 & $-3,1$ \\
\hline 2008 & LMC industrial & Captura industrial & Dif. $(\%)$ \\
\hline Jurel XV-II & 147.440 & 166.780 & 13,1 \\
\hline Jurel III-X & 1.324 .907 & 686.888 & $-48,2$ \\
\hline Anchoveta XV-II & 1.094 .986 & 534.331 & $-51,2$ \\
\hline Anchoveta III-IV & 50.410 & 4.275 & $-91,5$ \\
\hline Anchoveta V-X & 183.920 & 182.389 & $-0,8$ \\
\hline Sardina común V-X & 225.150 & 222.952 & $-1,0$ \\
\hline 2007 & LMC industrial & Captura industrial & Dif. (\%) \\
\hline Jurel XV-II & 144.400 & 172.587 & 19,5 \\
\hline Jurel III-X & 1.297 .547 & 1.081 .861 & $-16,6$ \\
\hline Anchoveta XV-II & 1.094 .986 & 639.613 & $-41,6$ \\
\hline Anchoveta III-IV & 50.410 & 6.706 & $-86,7$ \\
\hline Anchoveta V-X & 185.856 & 178.366 & $-4,0$ \\
\hline Sardina común V-X & 102.720 & 95.151 & $-7,4$ \\
\hline 2006 & LMC industrial & Captura industrial & Dif. (\%) \\
\hline Jurel XV-II & 126.350 & 153.694 & 21,6 \\
\hline Jurel III-X & 1.135 .097 & 1.181 .869 & 4,1 \\
\hline Anchoveta XV-II & 1.071 .110 & 428.388 & $-60,0$ \\
\hline Anchoveta III-IV & 54.385 & 11.307 & $-79,2$ \\
\hline Anchoveta V-X & 170.984 & 168.525 & $-1,4$ \\
\hline Sardina común V-X & 89.870 & 81.358 & $-9,5$ \\
\hline 2005 & LMC industrial & Captura industrial & Dif. (\%) \\
\hline Jurel XV-II & 133.886 & 162.868 & 21,6 \\
\hline Jurel III-X & 1.202 .920 & 1.231 .008 & 2,3 \\
\hline Anchoveta XV-II & 1.041 .320 & 904.057 & $-13,2$ \\
\hline Anchoveta III-IV & 56.140 & 10.940 & $-80,5$ \\
\hline Anchoveta V-X & 170.925 & 162.901 & $-4,7$ \\
\hline Sardina común V-X & 87.543 & 60.037 & $\begin{array}{c}-31,4 \\
\text { (continúa) }\end{array}$ \\
\hline
\end{tabular}


2004

Jurel XV-II

Jurel III-X

Anchoveta XV-II

Anchoveta III-IV

Anchoveta V-X

Sardina común V-X

2003

Jurel XV-II

Jurel III-X

Anchoveta XV-II

Anchoveta III-IV

Anchoveta V-X

Sardina común V-X

2002

Jurel XV-II

Jurel III-X

Anchoveta XV-II

Anchoveta III-IV

Anchoveta V-X

Sardina común V-X
LMC industrial

134.425

1.207 .772

1.385 .196

60.120

129.960

75.800

LMC industrial

122.425

1.207 .772

847.696

61.650

149.882

90.204

LMC industrial

21.462

1.338 .000

252.080

44.125

163.020

119.250
Captura industrial

Dif. (\%)

16,3

156.335

1.241 .146

1.234 .290

26.781

131.864

71.109

2,8

$-10,9$

$-55,5$

1,5

$-6,2$

Captura industrial

Dif. (\%)

142.043

16,0

1.240 .743

2,7

326.820

$-61,4$

27.686

$-55,1$

86.362

$-42,4$

40.310

$-55,3$

Captura industrial

Dif. (\%)

403,4

2,6

342,5

$-99,5$

$-62,8$

$-69,3$

Hay un antecedente aún más fuerte para descartar de plano que la captura por debajo de la cuota asignada sea el resultado de un ejercicio de poder de mercado de armadores nacionales ya sea actuando en forma unilateral o en forma coordinada. Me refiero a la participación de Chile en el mercado mundial en los distintos productos que tienen como insumos las capturas provenientes de las pesquerías del jurel, anchoveta y en menor medida sardina. Me refiero a los mercados de la harina y aceite de pescado, conservas y congelados. En el caso de la harina de pescado, la producción en Chile alcanzó el 14\% de la producción mundial en el 2008 (673 mil de 4 millones 818 mil toneladas $)^{20}$, participación que se ha mantenido prácticamente constante en los últimos años. La situación no es muy distinta en la producción de aceite de pescado, donde la producción en Chile no supera el 18\%; y en cuanto al jurel congelado, Chile representa un $13 \%$ de la oferta mundial.

${ }^{20}$ Todos los datos que uso en esta sección provienen de IFFO, FAO y Oilworld. 
Alguien puede decir que estos números de participación no son pequeños. Es cierto, pero detrás de estos números no hay una compañía sino varias. De hecho una estimación gruesa de participación de la mayor compañía Chilena llega al 5\% para sus distintos productos (en la página web de Corpesca, www.corpesca.cl, dice que su producción anual de harina de pescado representa un $6 \%$ de la oferta mundial) ${ }^{21}$. Difícilmente uno puede pensar que una compañía con una participación del $5 \%$ pueda mover un mercado; menos aun cuando hay una restricción de capacidad - la cuota individual asignada - de por medio. Por último, no hay que olvidar que estos productos finales compiten a su vez con otros sustitutos cercanos. El jurel congelado, por ejemplo, compite con muchos otros tipos de pescados congelados. En resumen, es absurdo pensar que una compañía nacional (o internacional) pueda tener incentivos en capturar menos de lo asignado por razones de manipulación de precios de los productos finales.

\section{2. ¿Hay problemas en los mercados internos?}

Tal como se explica en la sección 2.5, que el mercado internacional sea competitivo no elimina en forma automática la posibilidad que existan problemas de competencia, de eficiencia asignativa, en el mercado local de los productos finales — como resultado de los costos de transporte y mayor concentración de mercado. La forma de afectar la competencia, especialmente por las compañías con mayores cuotas, sería "desviando" venta desde el mercado local hacia el mercado internacional con la idea de levantar los precios de los productos finales en el mercado local (los precios en el mercado internacional están dados). Hay varias reacciones al respecto. La primera reacción es teórica y ya fue expuesta en la misma sección 2.5 y básicamente se refiere a la imposibilidad de mantener rentas oligopólicas en equilibrio dados los incentivos que tendrían las empresas para "mover primero"22 en el mercado nacional, vía la venta de cuotas a terceros.

${ }^{21}$ Corpesca tiene cerca del $80 \%$ de las cuotas en la zona norte, y de la Tabla $\mathrm{N}^{\circ} 1$ se observa que el tonelaje capturado en las pesquerías en dicha zona (XV-II) ha fluctuado entre 25\% el año 2003 y 48\% el año 2004 del total. Tomemos $40 \%$. Suponiendo que todas las compañías muestren una distribución similar del insumo entre los distintos productos finales (harina, aceite, congelados y conservas), la participación de Corpesca en el mercado del jurel congelado, por ejemplo, sería $0,8 * 0,4 * 0,13 *=4 \%$

${ }^{22}$ Es decir, para implementar sus soluciones Stackelberg. 
Pero aun desconociendo esta explicación teórica, hay varios otros elementos, de corte empírico, que apoyan la tesis de competencia en el mercado interno, es decir, la tesis de que no hay daños a los consumidores locales vía restricción o desvío de producción.

Lo primero que uno podría mirar es la concentración de mercado para cada uno de los productos finales. Las cuotas individuales, las capturas en las distintas regiones y el volumen de importaciones, cuando las hay, nos permiten obtener una estimación de las participaciones en el mercado interno. En dicho ejercicio vamos a suponer que todas las compañías nacionales muestran una distribución más o menos similar del insumo (i.e., captura) entre los distintos productos finales (i.e, harina, aceite, congelados y conservas). Veamos qué ocurre con la harina de pescado. Podemos partir por obviar las importaciones.

En la zona norte, Corpesca cuenta con casi el $80 \%$ de las cuotas y de acuerdo a la Tabla $\mathrm{N}^{\circ} 1$, las toneladas capturadas en la zona norte representan aproximadamente el $40 \%$ del total. Con estos números y supuestos, la participación de Corpesca en el mercado local de harina de pescado llegaría al 32\% — obviamente que estos números cambiarán si Corpesca se concentra mucho más en la elaboración de algunos productos que en otros o si se enfoca mucho más a servir el mercado internacional o viceversa; pero aun así estos números nos entregan órdenes de magnitud. El tamaño de la segunda compañía, Alimar, en términos de cuotas/capturas sería de aproximadamente 13\% (tal como se desprende del cuadro 3 de la consulta de Lota Protein al TDLC). Siguiendo la misma lógica, la participación de Alimar en el mercado local de harina de pescado llegaría a $8 \%$. Después vendrían varias compañías, ocho, con participaciones entre 5 y $8 \%$. En el caso del aceite de pescado las participaciones anteriores son aun menores debido a las importaciones, que según cifras de IFFO y FAO alcanzaron un $50 \%$ en el 2008 (también hay exportaciones que harían caer aún más los números anteriores). La participación de Corpesca debiera caer a por lo menos $21 \%$ (sin contar las exportaciones).

¿Nos preocupan estos números de concentración desde un punto de vista de libre competencia? En ausencia de un análisis más detallado de datos de precios y costos es difícil dar una respuesta precisa. Se podría adelantar que estos números de concentración son menores que los que se observan en varios otros mercados en el país. Pero hay, eso sí, varios otros elementos que nos pueden ayudar en este análisis de 
competencia sin recurrir a datos de costos, precios y cantidades individuales. En este sentido, un segundo elemento es qué tan importantes son los costos de transporte. Aun si lo fueran para llegar a (o venir de) los mercados internacionales más lejanos, su importancia para nuestros mercados locales se diluye ya que el mayor productor del mundo de muchos de estos productos finales es Perú. Según cifras del IFFO y FAO, en el 2008 Perú produjo el 30\% de la harina de pescado y el 27\% del aceite de pescado. A diferencia de Chile, Perú además exporta prácticamente todo lo que produce. Por esto mismo, es imposible pensar que los productores locales gozan de poder de mercado en el mercado local dada la oferta perfectamente elástica del Perú.

Un tercer elemento es que si efectivamente los consumidores locales de productos como el aceite y harina de pescado estuviesen enfrentando precios anticompetitivos, que por altos costos de transporte no pudieran arbitrar, sería ingenuo pensar que estos consumidores no hubiesen recurrido ya a las autoridades de libre competencia. Esto porque no se trata de muchos pequeños consumidores con poca información, sino todo lo contrario. Gran parte de la harina de pescado producida en Chile es utilizada para la formulación de alimentos destinados a la acuicultura (salmones, camarones, anguilas, etc.) así como a la crianza de cerdos y aves.

Pero el último y más contundente de todos los elementos proviene directamente del marco teórico desarrollado en la sección 2.5; en particular la expresión (1) y la discusión que le sigue. Si efectivamente hubiese problemas de competencia en el mercado local, uno necesariamente debiera observar compañías, especialmente las con mayores cuotas, "desviando" venta desde el mercado local hacia el mercado internacional con la idea de levantar los precios de los productos finales en el mercado local (los precios en el mercado internacional están dados). Simultáneamente uno debiera observar a las compañías con pocas cuotas, como Lota Protein, vendiendo todo o prácticamente todo en el mercado local. Realicemos un ejercicio numérico simple: a partir de la expresión (1), ¿de cuánto debiera ser la cuota de una compañía pequeña para querer vender todo en el mercado local? Tomemos, ejemplo, harina de pescado. Aproximadamente el $70 \%$ de la producción de harina de pescado se exporta (en el 2008 se exportaron 478 mil toneladas de un total producido de $673 \mathrm{mil}$ ), lo que nos entrega un valor de $\mathrm{q}^{\mathrm{n}}=0,3$ en la ecuación (1). Por otro lado, hoy 
habría 14 actores con cuotas para capturar peces, principalmente jurel y anchoveta, destinados a producción de harina de pescado: dos actores en la zona norte y 12 en la zona centro-sur (los once listados en el Cuadro $\mathrm{N}^{\circ} 3$ de la consulta de Lota Protein y los "otros" como el duodécimo) $)^{23}$. Con esto tenemos que $\mathrm{q}^{\mathrm{n}} / \mathrm{n}=0,3 / 14=2,1 \%$. Según esta lógica, cualquier compañía con una cuota igual o menor que $2,1 \%$ (del total capturado en el país) debiera dedicar el total de su captura a la producción de harina para el mercado local, y cualquier otra con una participación mayor debiera repartirse entre el mercado local y el internaciona ${ }^{24}$.

Todas las compañías de mayor tamaño efectivamente participan en ambos mercados, algo que ocurriría independientemente del nivel de competencia en el mercado local, ya que este último es capaz de absorber sólo un $30 \%$ de la producción. Más informativo para nuestro análisis es entonces lo que ocurre con una compañía que dispone de una cuota pequeña, como Lota Protein, que tiene $1,8 \%$ de la cuota global entregada para la zona centro-sur. Si el mercado local sufriera problemas de competencia, i.e., altos precios, Lota Protein debiera vender el $100 \%$ de su producción en el mercado local — esto es lo que dice la expresión (1). Lo que observamos, sin embargo, es que parte importante de la producción de harina de Lota Protein tiene como destino los mercados internacionales ${ }^{25}$. La evidencia es abundante y contundente entonces de que no hay problemas de eficiencia asignativa, o dicho de otra forma, de que no hay abuso de poder de mercado ya sea en forma unilateral o coordinada en los mercados internos.

Quisiera concluir esta sección con una observación que tiene relación con el posible poder de compra (i.e., poder monopsónico o, más bien, oligopsónico) que pesqueras industriales, aquellas integradas verticalmente, pudieran ejercer sobre pescadores artesanales al momento de comprarles su captura para la elaboración de los distintos productos

${ }^{23}$ El cuadro 3 de la consulta de Lota Protein se reproduce en la Tabla $\mathrm{N}^{\circ}$ 2. No quiero desviar la atención del lector hacia entender cómo Lota Protein construyó este cuadro. Simplemente lo tomo como tal para este ejercicio.

${ }^{24}$ Aclaración técnica: hay que corregir la solución Cournot cuando algunas compañías, las pequeñas, usan el total de la cuota ya que "dejan de ser estratégicas".

${ }^{25}$ Para reforzar aún más este argumento, nótese que en su consulta Lota Protein dice expresamente que le gustaría contar con más cuota para entrar al mercado del jurel congelado. Pero éste es un mercado esencialmente internacional en el que Chile aporta el $13 \%$ de la oferta mundial; la demanda interna de Chile es despreciable. 
finales. Alguien pudiera decir que la concentración de mercado sí importa porque el ejercicio de poder de compra se facilita en la medida que se reduce el número de actores industriales. Para analizar esta posibilidad podemos ir nuevamente a la sección 2.3 y hacer la siguiente pregunta: Si las pesqueras industriales están haciendo un total uso de sus cuotas individuales en la elaboración de productos finales, ¿pueden tener incentivos para comprar menos del total de la cuota asignada a pescadores artesanales? La respuesta es no por el mismo motivo Stackelberg que lleva a las firmas a tratar de apropiarse de una mayor fracción de las rentas oligopólicas, ahora comprando producción, no cuotas, a terceros. Al comprar producción a terceros la firma industrial se está comprometiendo creíblemente a procesar esa captura (este compromiso para producir más es exactamente lo que logra un contrato de producción a futuro en la línea de Allaz y Vila, 1993).

Para ahondar aún más en esto vamos al caso extremo en que existe una sola pesquera industrial que de poseer el 100\% de la cuota global de captura la utilizaría por completo (en términos de la Figura $\mathrm{N}^{\circ} 1$ estamos diciendo que la cuota global es menor que la cantidad monopólica $\mathrm{q}^{\mathrm{m}}$ ). Supongamos ahora que una fracción de la cuota global está en manos de varios productores artesanales sin capacidad de procesar la captura para transformarla en productos finales. El monopolista industrial tiene todos los incentivos para comprar el total de la captura a los artesanales (y a un precio que cubra todos los costos relevantes que llevan a los artesanales a pescar el total de la cuota asignada), ya que hay un excedente positivo. Si bien es evidente que se pesca el total de la cuota en manos de los artesanales, disipando cualquier problema de eficiencia o libre competencia, lo que resulta menos evidente es cuánto del excedente (neto de costos) asociado a la cuota de los artesanales finalmente se queda con ellos y cuánto con el industrial. A medida que el número de firmas industriales aumenta, el poder de negociación de los artesanales mejora y uno esperaría que retengan un mayor porcentaje del excedente de escasez que significa fijar una cuota global. Nuevamente vemos que la pesca es distinta, ya que hay diferencia con otros mercados donde puede haber problemas de poder de compra ${ }^{26}$; aquí

${ }^{26}$ El mercado de la leche es un buen ejemplo donde este tipo de problemas de poder de compra se han discutido ampliamente. Aquí el poder de compra sí tiene consecuencias de eficiencia o libre competencia, ya que inevitablemente se refleja en que productores de leche socialmente eficientes no producen por los bajos precios que reciben. 
los problemas de poder de compra no se ven necesariamente reflejados en menor captura, y esto porque hay una cuota global que restringe la oferta.

\section{3. ¿Qué tan transferibles son las cuotas de pesca?}

Quizá la transferibilidad de las cuotas sea el asunto más relevante, si no el único, en la argumentación de varios analistas, ya que tiene directa relación con las supuestas "dificultades" que podría tener una compañía para aumentar sus cuotas de pesca. De hecho, hay algunos que proponen la utilización de subastas como mecanismo de asignación inicial de cuotas, no tanto para resolver los supuestos problemas de competencia (v. gr., acaparamiento estratégico de cuotas, colusión, etc.) sino más bien para escapar de supuestos altos costos de transacción (y asimetrías de información $)^{27}$, que estarían impidiendo un fluido comercio de cuotas entre los distintos actores pesqueros, tanto existentes como posibles entrantes.

Desde el punto de vista de la libre competencia y sabiendo que las compañías han utilizado el total de sus cuotas, lo que queda por revisar en esta sección es la existencia de cualquiera de estos dos factores: (i) ejercicio de poder de mercado en el mercado de cuotas y (ii) importantes costos de transacción. Si bien la presencia de costos de transacción puede resultar en una sub-óptima asignación de recursos - a menos que la asignación inicial de las cuotas sea la socialmente eficiente-, cuesta asociar costos de transacción con problemas de libre competencia, es decir, con una conducta anticompetitiva por parte de una o varias firmas. Sería entonces más razonable hablar de problemas de asignación de recursos. En todo caso y tal como vimos en la sección 2.6, la presencia de cualquiera de estos dos factores resultaría en pérdidas de eficiencia productiva pero no de eficiencia asignativa. Esto significa que el bienestar de los consumidores no se verá afectado por la existencia de uno o ambos factores; sólo el bienestar de los productores.

El mercado que utilizo para analizar ambos aspectos - ejercicio de poder de mercado y costos de transacción - es nuevamente el mer-

${ }^{27}$ Las asimetrías de información dificultan una transacción tanto como otros costos directos, por lo tanto se pueden pensar como parte de los costos de transacción. 
cado de venta y compra de cuotas de pesca en la zona centro-sur. En la Tabla $\mathrm{N}^{\circ} 2$ se reproduce el cuadro 3 de la consulta de Lota Protein con las cuotas individuales, medidas como porcentaje de la cuota global, para el 2009. Bajo una mirada convencional a las participaciones de mercado y número de actores uno podría concluir que el mercado diseñado por Lota Protein en la consulta es un mercado desconcentrado y, por lo mismo, competitivo. De hecho, si se calcula el índice de concentración de Herfindahl se obtendría un valor muy inferior al de muchos mercados que actualmente operan en el país. Incluso me atrevería a afirmar que cualquier proposición de fusión entre dos firmas, quizá con excepción de las dos primeras, sería aprobada sin ningún problema por una autoridad de competencia. Casos al respecto hay muchos, basta ver lo que ha ocurrido en la industria bancaria y en supermercados.

Pero toda esta discusión es incompleta ya que cualquier mercado de transacciones de cuotas de pesca requiere de una mirada distinta; los compradores y vendedores son las mismas empresas. Por lo mismo, y tal como vimos en la sección 2.6, no basta con que un actor sea de tamaño importante para que tenga incentivos para ejercer poder de mercado, se requiere además que su asignación inicial se aleje en forma

\section{TABLA N ${ }^{\circ}$ 2: $\quad$ CUOTAS INDIVIDUALES EN LA ZONA CENTRO-SUR}

Empresa Porcentaje participación 2009

$\begin{array}{lr}\text { Alimar } & 13,4 \\ \text { El Golfo } & 12,8 \\ \text { SPK } & 11,4 \\ \text { Itata } & 11,1 \\ \text { San José } & 10,1 \\ \text { Camanchaca } & 9,8 \\ \text { Bío Bío } & 9,1 \\ \text { FoodCorp } & 8,3 \\ \text { Landes } & 5,5 \\ \text { Nacional } & 5,0 \\ \text { Lota Protein } & 1,8 \\ \text { Otros } & 1,7 \\ & \\ \text { Total } & 100\end{array}$

Fuente: Consulta de Lota Protein al Tribunal de Defensa de la Libre Competencia, Tabla $\mathrm{N}^{\circ} 3$. 
importante de su asignación socialmente eficiente. Sólo así le convendría restringir la venta de cuotas cuando su asignación inicial esté por encima del óptimo social o, alternativamente, restringir la compra de cuotas cuando su asignación inicial esté por debajo del óptimo social. Pero la historia no termina ahí. La posibilidad de ejercer poder de mercado en un mercado de cuotas se reduce aún más cuando hay varios actores estratégicos, donde algunos venden y otros compran cuotas, todo dependiendo de la asignación inicial (Malueg y Yates, 2009) ${ }^{28}$.

De hecho y a modo de ilustración, no es aventurado predecir la solución socialmente óptima para un mercado donde hay sólo dos actores estratégicos de tamaño similar, uno en el lado de la oferta y el otro, por supuesto, en el lado de la demanda, en una suerte de monopolio bilateral. Esta particularidad en la forma en que se ejerce poder de mercado en un mercado de cuotas, más la presencia de varios actores de tamaños no muy distintos permiten descartar que la pérdida de eficiencia productiva en el mercado de cuotas de la zona centro-sur, si es que existe, sea el resultado del ejercicio de poder de mercado (por el lado de restringir la venta de cuotas $)^{29}$.

Antes de pasar a revisar la segunda posible fuente de pérdida de eficiencia productiva, esto es, la presencia de costos de transacción, es útil hacerse las siguientes preguntas. La primera pregunta: ¿Cuál sería el objetivo de mantener un comportamiento colusivo en el mercado de cuotas (no de productos finales)? ¿Para levantar los precios en el mercado de los productos finales, a saber, harina y aceite de pescado,

28 Estos autores estudian formalmente el equilibrio para mercados de cuotas con este tipo de estructura oligopólica-oligopsónica y efectivamente encuentran que rápidamente la solución de equilibrio se aproxima a la socialmente óptima (de hecho el precio de equilibrio siempre es el socialmente óptimo, independiente del número de firmas y la asignación inicial). No es difícil producir una simulación con, por ejemplo, ocho firmas simétricas y mostrar que la solución es muy cercana a la socialmente eficiente.

29 Uno igualmente podría levantar el caso opuesto, que grandes firmas estén ejerciendo poder monopsónico (comprando menos de lo que es socialmente eficiente) ya que su asignación inicial en 2001 fue inferior a su asignación socialmente eficiente. Y si fuera así, Lota Protein y también otras compañías podrían tener más cuotas de lo socialmente eficiente. Al respecto, es interesante constatar que en el mercado de cuotas de contaminación de dióxido de azufre en EE.UU. - cuotas transferibles que fueron entregadas gratuitamente en base a emisiones históricas - , los grandes actores están por el lado de la compra y no por el lado de la venta (Liski y Montero, 2011). En todo caso estos autores no encuentran ejercicio de poder monopsónico. 
congelados y conservas? Pero si ya demostramos que las cuotas están siendo utilizadas en su totalidad y que no hay desvío de ventas desde los mercados internos hacia el extranjero con tal propósito.

Luego, si el comportamiento colusivo no era para manipular los precios en el mercado de los productos finales, ¿era entonces para manipular los precios en el mercado de cuotas? Pero aquí aparece la segunda pregunta. ¿Qué forma podría tomar la colusión en un mercado de cuotas sabiendo que todas ellas van a ser usadas y donde hay varios agentes estratégicos de tamaños no muy distintos, tal como muestra la Tabla $\mathrm{N}^{\circ}$ 2? En dicho cartel algunos miembros querrían manipular los precios hacia la baja, los que estarían por comprar más cuotas, mientras que otros querrán manipular los precios hacia el alza, los que quieren vender cuotas. Lo que quiero decir con esto es que a diferencia de un mercado convencional donde los agentes estratégicos están todos por el lado de la oferta y los no-estratégicos (consumidores) por el lado de la demanda, es difícil hablar de colusión en un mercado de cuotas donde algunos agentes estratégicos pueden estar por el lado de la oferta y otros por el lado de la demanda. Quisiera terminar este punto diciendo que dado el volumen de transacciones es evidente que el negocio de las pesqueras no está en la compra y venta de cuotas, sino en la venta de productos finales.

Pasemos ahora a revisar la segunda posible fuente de pérdida de eficiencia productiva: los costos de transacción. Además de insistir en que cuesta asociar costos de transacción con libre competencia, ya que dichos costos no son producto de una conducta anticompetitiva de una o varias firmas, quisiera partir por aclarar que la ausencia de transacciones de cuotas no es necesariamente sinónimo de altos costos de transacción (y asimetrías de información). De hecho las transacciones debieran reducirse a un mínimo cuando se llegue a la asignación socialmente eficiente y las valoraciones de las firmas por las cuotas no cambien mucho en términos relativos. Tal como muestran Newell et al. (2005) para Nueva Zelanda, sin embargo, las transacciones no debieran desaparecer por completo, especialmente las de corto plazo (v.gr., arriendos de cuotas por un año o menos), para acomodar fluctuaciones en ese plazo en las valoraciones relativas de las firmas. Este mismo paper muestra que después de un tiempo las transacciones de largo plazo (i.e., venta de cuotas) efectivamente se reducen fuertemente. 
¿Cómo ha sido la actividad en el mercado de cuotas de pesca, en particular para la zona centro-sur, a partir del año 2001 con la entrega de las cuotas individuales según la Ley 19.713? Lota Protein documenta algunas transacciones en su consulta (pp. 55 y 56), las que por cierto están muy por debajo de las documentadas por la Fiscalía Nacional Económica (FNE) y Subpesca en sus respectivas presentaciones al TDLC a raíz de la consulta de Lota Protein. En la Tabla $\mathrm{N}^{\circ} 3$ se reproduce el cuadro de transacciones presentado por Subpesca para la pesquería del jurel (datos para las otras pesquerías se encuentran en el informe de Subpesca).

Si bien muchas de estas transacciones, al igual que las indicadas en la consulta, constituyen traspasos de embarcaciones de pesqueras que se retiran del negocio o son absorbidas por otras, es interesante observar que igualmente hay transacciones entre pesqueras activas, como son las transacciones de FoodCorp a Camanchaca y de El Golfo a Camanchaca. Además Subpesca documenta en su informe la entrada de varios nuevos armadores a partir del $2001^{30}$. A pesar de esto último, vale la pena enfatizar que la entrada de nuevos actores no es una condición necesaria para contar con mercados competitivos y de bajos costos de transacción.

TABLA $\mathrm{N}^{\circ}$ 3: $\quad$ TRANSACCIONES DE CUOTAS Y EMBARCACIONES

\begin{tabular}{|c|c|c|c|c|c|c|}
\hline \multirow[b]{2}{*}{ Año } & \multicolumn{2}{|c|}{ III-IV Región } & \multicolumn{2}{|c|}{ V-IX Región } & \multicolumn{2}{|c|}{ X Región } \\
\hline & Núm. naves & $\%$ cuotas & Núm. naves & $\%$ cuotas & Núm. naves & $\%$ cuotas \\
\hline 2001 & 23 & 14,8 & 62 & 36,1 & 57 & 32,6 \\
\hline 2002 & 11 & 7,9 & 15 & 7,5 & 19 & 12,6 \\
\hline 2003 & 5 & 3,6 & 14 & 2,4 & 9 & 2,5 \\
\hline 2004 & 5 & 3,6 & 20 & 13,9 & 17 & 10,6 \\
\hline 2005 & 6 & 2,8 & 13 & 6,2 & 13 & 9,2 \\
\hline 2006 & 3 & 0,9 & 9 & 8,6 & 9 & 9,9 \\
\hline 2007 & 1 & 0,2 & 2 & 1,4 & 2 & 1,4 \\
\hline 2008 & 0 & 0 & 2 & 1,2 & 2 & 1,0 \\
\hline 2009 & 0 & 0 & 0 & 0 & 0 & 0 \\
\hline
\end{tabular}

Nota: Las cifras de transacciones de naves en la tabla no corrigen el hecho que muchas naves están presentes en más de una zona. Según personal de Subpesca, con dicha corrección el total de 319 transacciones de naves que muestra la tabla se reduce a 162 naves.

${ }^{30}$ En su informe Subpesca habla de 12 nuevos armadores que concentran el $25,7 \%$ de la cuota en la pesquería del jurel. 
El patrón de transacciones que se observa en la zona centro-sur no es distinto al observado en Nueva Zelanda, por ejemplo, donde gran parte de las transacciones de ventas de cuotas coinciden con la salida de actores. Tal como documentan Newell et al. (2005), a partir de 1990 se observó una caída neta de $37 \%$ en el número de propietarios de cuotas (quota owners), lo que se ve reflejado en un mayor volumen de transacciones de venta en tal año (un promedio de 15\% de la cuota global) para estabilizarse en un valor mucho menor, cercano al 5\%, al cabo de cuatro años. Esto no es muy distinto a lo que se observa en la Tabla $\mathrm{N}^{\circ}$ 3: un período de consolidación con un número importante de transacciones seguido por una caída gradual en las mismas. Que el volumen de transacciones haya caído fuertemente en los últimos años no es sorpresa, y mucho menos debe ser interpretado como un signo de altos costos de transacción. Esto porque no se puede esperar un volumen de ventas de cuotas muy importante una vez que se alcanza, en términos esperados, el equilibrio de largo plazo. Y la razón es que las valoraciones relativas de largo plazo de las firmas por cuotas no cambian tan frecuentemente.

Lo que sí se observa en la mayoría de los mercados de cuotas de Nueva Zelanda, en algunas pesquerías relativamente pequeñas en Chile (aquellas donde las cuotas fueron licitadas, como en el bacalao de profundidad y el langostino colorado), y posiblemente también en la mayoría de las pesquerías en Islandia, es un activo mercado de arriendo de cuotas (léase market) por períodos cortos de un año o incluso menos en el caso de Nueva Zelanda. Este mercado de arriendo de cuotas no puede surgir en la zona centro-sur por la forma en que están definidas las cuotas individuales en la Ley 19.713, que sólo permite la transacción de cuotas vía la transacción de embarcaciones. Por lo mismo, la autoridad tiene que avanzar en el establecimiento de cuotas individuales autónomamente transferibles, es decir, con prescindencia de una embarcación o cualquier otra infraestructura pesquera, tal como hoy en día ocurre en los mercados de cuotas más importantes y exitosos del mundo, como son los mercados en Islandia y Nueva Zelanda. Esto va a permitir los ajustes de corto plazo a que hacía mención anteriormente.

En cuanto a la segunda parte del argumento — que aquí no ha existido un mercado secundario - tengo tres reacciones. La primera es que el mercado secundario en que muchos están pensando es el de venta de cuotas, no el mercado de arriendo de cuotas. $\mathrm{Y}$ en ese sentido es difícil decir que el mercado de ventas en la zona centro-sur no ha 
funcionado, desde el momento en que se han observado numerosas transacciones.

Y además éste es un mercado en que el volumen de transacciones no puede ser alto por la naturaleza de las transacciones: las transacciones se producen por diferencias entre las valoraciones de largo plazo de las empresas. Quiero insistir en esto último. Éste no es el mercado del pan con grandes volúmenes de transacciones desde productores de pan a consumidores de pan (i.e., toda la población). Si lo fuera tendríamos que exigir que el $100 \%$ de la cuota se transase en cada período (cada día quizá), lo que es absurdo.

La segunda reacción, muy relacionada con lo anterior, es que algunos olvidan que lo que justifica económicamente una transacción de venta de cuotas no es que el retorno marginal de una compañía en particular sea positivo (en términos de nuestro modelo, que $\mathrm{P}\left(\mathrm{q}^{\mathrm{TAC}}\right)$ sea mayor que $\mathrm{c}_{\mathrm{LP}}$, el costo de explotación de largo plazo de dicha compañía) sino que el retorno marginal tiene que ser mayor que el de la compañía que vende la cuota (es decir, que $\mathrm{c}_{\mathrm{LP}}$ sea menor que $\mathrm{c}_{\mathrm{V}}$, el costo de explotación de largo plazo del vendedor). Por lo mismo, y a diferencia de lo que ocurre en un mercado convencional donde empresas venden a consumidores, que una compañía no "haya encontrado vendedores" no significa en absoluto que se hayan dejado de hacer ajustes de largo plazo socialmente beneficiosos.

Y la tercera reacción es que en mercados de cuotas en Chile aún más concentrados que el de la zona centro-sur, como son, por ejemplo, los del bacalao de profundidad y langostino colorado, se observa un importante volumen de transacciones, especialmente en lo que se refiere a contratos de arriendo. En resumen, no hay evidencia de pérdidas de eficiencia productiva de largo plazo. En todo caso, como el sistema actual impide ajustes de corto plazo, uno sí puede hablar de costos de transacción, que impiden tales ajustes y que se originan en la definición del activo que se transa.

\section{Subasta como mecanismo de asignación de cuotas}

A pesar de que a la luz de la teoría y los datos no se observan problemas de libre competencia o, si se quiere, de asignación de recursos, salvo por los ajustes de corto plazo a que hacía mención en la sección anterior, es igualmente útil preguntarse qué se podría ganar o 
perder con un cambio en la forma de asignar inicialmente las cuotas individuales transferibles desde un sistema de asignación gratuito basado en capturas históricas (grandfathering) a uno de subasta. Y cuando digo subasta, estoy pensando en diseños de licitación basados exclusivamente en precios, es decir, aquellos que tienen como único objetivo asignar las cuotas a aquellos agentes que más las valoran. Hay que aclarar que independiente del mecanismo de asignación inicial, las cuotas individuales son transferibles una vez concluida la asignación inicial. Voy a organizar la discusión de esta sección en dos partes. En la primera voy a desarrollar algunas observaciones generales de corte más bien empírico, incluyendo una mirada a las subastas de pesca en Chile, y en la segunda voy a ofrecer una discusión conceptual.

\subsection{Observaciones generales}

Quizá un buen punto de partida en esta discusión general es preguntarse qué tan comunes son las subastas de cuotas de pesca en comparación con los sistemas de cuotas individuales transferibles entregadas gratuitamente. Lo cierto es que son muy poco comunes. En la gran mayoría de los casos las cuotas ha sido asignadas en forma gratuita. Las únicas excepciones son algunas pesquerías más pequeñas en Chile — bacalao de profundidad, orange roughy, langostino amarillo y langostino colorado - y las experiencias, poco exitosas, de algunas pesquerías en Rusia y Estonia a principio de los 2000. Según Anferova et al. (2005), la razón por la cual Rusia intentó con un sistema de subastas a partir del 2001 fue para atraer más recursos al Estado y hacer más transparente la asignación de las cuotas (i.e., terminar con la corrupción que existía bajo la asignación gratuita). Rusia decidió, sin embargo, abandonar el sistema de cuotas pocos años más tarde, en 2003, debido a los malos resultados económicos de las compañías pesqueras y al aumento en la pesca ilegal. La historia en Estonia es muy similar (Eero et al., 2005). Sin duda que uno no puede llegar y extrapolar de estas experiencias, pero así y todo hay una lección de economía política interesante en las razones que impulsaron el cambio al sistema de subastas.

La economía política en la asignación inicial de "derechos de propiedad" o permisos de uso de un recurso se extiende a otros recursos, como son los permisos de contaminación (Tietenberg, 2006). Al igual que con las cuotas de pesca, la razón principal que impulsa el 
uso de subastas no es la de una asignación inicial eficiente, ya que eso se logra con la transferibilidad del permiso, sino que la recaudación que se obtenga, la cual eventualmente se puede usar para reducir otros impuestos en la economía (en un contexto de equilibrio parcial estas recaudaciones son simples transferencias). En la práctica, sin embargo, los permisos de contaminación se han entregado casi en su totalidad en forma gratuita: 33 basados en emisiones históricas (Tietenberg, 2006). El mejor ejemplo de esta discusión es la asignación inicial de permisos de carbono. La lección aquí es que el uso de subastas como mecanismo de asignación inicial no pasa por un tema de eficiencia o competencia sino por un tema distributivo.

Por último, es útil revisar lo que ha ocurrido con las subastas de cuotas de pesca en Chile en las cuatro pesquerías anteriormente señaladas. No tengo todos los datos para realizar un análisis empírico detallado del funcionamiento de estas subastas, las que datan desde 1992. En la Tabla $\mathrm{N}^{\circ} 4$ presento un resumen con las participaciones de los ganadores en la subasta inicial, aquella en que se repartió el total de la cuota global entre cada una de las pesquerías en cuestión (la subasta inicial para el bacalao de profundidad y el langostino colorado fueron en 1992, para el langostino amarillo en 1996 y para el orange roughy en 1998).

TABLA N ${ }^{\circ}$ 4: $\quad$ PARTICIPACIONES DESPUÉS DE LA PRIMERA SUBASTA

\begin{tabular}{lcccc}
\hline Pesquera $\mathrm{N}^{\circ}$ & $\begin{array}{c}\text { Bacalao } \mathrm{p} . \\
(\%)\end{array}$ & $\begin{array}{c}\text { O. roughy } \\
(\%)\end{array}$ & $\begin{array}{c}\text { Langostino c. } \\
(\%)\end{array}$ & $\begin{array}{c}\text { Langostino a. } \\
(\%)\end{array}$ \\
\hline 1 & 20 & 23 & 50 & 25 \\
2 & 17 & 22 & 27 & 22 \\
3 & 15 & 21 & 17 & 19 \\
4 & 11 & 17 & 6 & 15 \\
5 & 10 & 14 & & 9 \\
6 & 9 & 2 & & 4 \\
7 & 5 & & & \\
8 & 5 & & & \\
9 & 4 & & & \\
10 & 2 & & & \\
11 & 2 & & & \\
Total & 100 & 100 & & \\
\hline
\end{tabular}


Aun entendiendo que estas pesquerías son bastante menores que las de la zona centro-sur, es interesante observar el nivel de concentración como resultado de la subasta. En el caso del bacalao, $82 \%$ de la cuota cayó en manos de seis pesqueras, concentración que se ha mantenido en el tiempo ${ }^{31}$. Las otras pesquerías muestran niveles de concentración aún mayores que también se han mantenido más o menos constantes en el tiempo. Lo único que quiero mostrar con estos números es que el nivel de concentración en la distribución de cuotas que se observa en la zona centro-sur no es inusual, todo lo contrario, y en consecuencia no se puede atribuir dicho nivel al hecho que las cuotas hayan sido inicialmente asignadas en base a captura histórica en vez de subastadas. Tal como explica Peña-Torres (2002), el grado de concentración que se observa en estas pesquerías es "probablemente el resultado de un proceso de ajuste óptimo, desde el punto de vista de eficiencia en costos de producción, dadas las características tecnológicas y de demanda que son relevantes en el negocio pesquero... Y esto como resultado de la presencia de economías de escala en distintas fases del negocio pesquero". Por esta misma razón es que Peña-Torres (2002) anticipa que aun cuando las subastas fueran diseñadas en forma apropiada (i.e., asignando a los que más valoran las cuotas) es "probable que se terminase observando escasa o nula entrada de nuevos competidores, particularmente en pesquerías donde ya existen empresas dominantes relativamente consolidadas".

\subsection{Discusión conceptual}

Visto que todas las cuotas están siendo utilizadas, que no hay "desvío" de venta de productos finales desde los mercados internos al extranjero por parte de quienes poseen cuotas mayores y que las firmas han realizados ajustes de largo plazo vía la transacción de cuotas, en esta sección quiero desarrollar algunos argumentos conceptuales adicionales para completar la tesis de que no hay razones de libre competencia para utilizar un mecanismo de subasta para la asignación inicial de cuotas de pesca. Por lo mismo, tampoco puedo invalidar el uso de subastas

${ }^{31}$ Usando simplemente datos provenientes de las subastas (lo que excluye transacciones de venta o arriendo), el índice Hefindahl se ha movido de 1.290 en 1992 a 1.245 en 2002. 
- aun cuando no terminen asignando inicialmente las cuotas a aquellos que más las valoren, ya que esto se corrige con la transferibilidad de las mismas - con objetivos de recaudación. De hecho, yo anticipo que de usarse un mecanismo de subasta más o menos bien diseñado (i.e., que tienda a asignar las cuotas a aquellos que más las valoran) para las pesquerías de la zona centro-sur, las cuotas terminarían en las mismas manos en que están hoy. El uso de subastas es al final una discusión de economía política que se aleja de los temas de libre competencia que nos han ocupado en este estudio.

Es ampliamente reconocido que una subasta bien diseñada implementa la asignación eficiente de un recurso u objeto (Milgrom, 2004; Krishna, 2002). Esto ha servido de pie para que algunos afirmen que cualquier otro mecanismo de asignación inicial de cuotas en las pesquerías que nos competen será inevitablemente ineficiente. Hay varios problemas con dicha afirmación.

Partamos por preguntarnos por qué la autoridad quisiera usar una subasta. La razón es simple: porque parte de la información relevante para decidir cómo asignar mejor los recursos, i.e., cuotas, está en manos de aquellos mismos que usarán dichos recursos, las empresas pesqueras. Si la autoridad tuviera un buen conocimiento de las características de las empresas pesqueras, tanto de las existentes como de las potenciales entrantes, podría en principio implementar la asignación eficiente sin necesidad de usar subastas - a menos que haya de por medio un objetivo de recaudación. En Montero (2008) desarrollo precisamente un mecanismo de subasta que le permitiría a la autoridad regulatoria, desinformada de las características de las firmas, implementar la asignación eficiente de cuotas de contaminación ${ }^{32}$. ¿Por qué no usar lo mismo para asignar cuotas de pesca? Hay dos razones. La primera es que a diferencia de lo que ocurre con la contaminación, en pesca la cuota global es exógena a las firmas y se fija de modo de asegurar la sustentabilidad del recurso en el largo plazo. En contaminación, la cuota global se fija en la subasta ya que es endógena a las características de las firmas: entre más barato sea descontaminar, menor debiera ser la cuota global de permisos. Ésa es la razón principal de por qué uno quisiera usar una subasta, como la propuesta en Montero (2008), para asignar permisos de contaminación.

${ }^{32}$ Es una implementación en estrategias dominantes ya que los pagos son del tipo Vickrey-Clarke-Groves (VCG). Para más detalle sobre este tipo de mecanismos véase Milgrom (2004). 
La segunda razón es dinámica, esto es, la mantención de la eficiencia productiva en el tiempo. Tal como muestran todas las experiencias con cuotas individuales transferibles tanto en Chile como en el mundo, para lograr eficiencia en la asignación de los recursos no basta con que la asignación inicial sea eficiente sino que se requiere que las empresas tengan suficiente flexibilidad para ajustarse en el tiempo a cambios en costos relativos (la importancia de esto lo muestran los volúmenes de transacciones, particularmente en la forma de arriendos, que se observan en distintas pesquerías tanto en Chile como en el resto del mundo). Y esto se logra con un sistema de cuotas individuales que sean fácilmente transferibles ex post, es decir, después de la asignación inicial. Por lo mismo, la ventaja inicial que consigue una subasta desaparece rápidamente: uno, porque los costos relativos de las empresas cambian y se requiere de nuevas transacciones, o dos, porque aun si los costos relativos no cambian, la transferibilidad permite acercarse al resultado de la subasta, si es eficiente, desde cualquier asignación inicial. Hay que enfatizar que las cuotas de pesca no pueden ser vistas como un objeto único indivisible que de caer en manos de alguien que las valore menos que un tercero sea difícil de transferir a consecuencia de asimetrías de información que puedan existir. Todo lo contrario, las cuotas son económicamente divisibles, lo que facilita enormemente su transferibilidad. Y esto es lo que se observa en la práctica, especialmente animada por un dinámico mercado de contratos de arriendo.

Algunos analistas han señalado que aun cuando las cuotas sean fácilmente transferibles (i.e., que se puedan transar en forma autónoma de las embarcaciones, tal como he sugerido en este estudio), eso no es suficiente para asegurar eficiencia productiva en el tiempo y, por lo tanto, igualmente se requiere un mecanismo de subastas para alcanzar dicho objetivo. El origen del problema radicaría, aparentemente, en que altos costos de transacción dificultarían el comercio fluido de cuotas y con ello la formación de una señal fuerte de precios respecto del valor de una cuota en el mercado. Y que la ausencia de una señal de precios, a su vez, crea asimetrías de información entre vendedores y compradores reforzando aún más los costos de transacción. Para entender el fondo de esta línea argumental es necesario explicar un par de cosas (además de insistir en muchas de las consideraciones desarrolladas en la discusión empírica de la sección 3.3). En primer lugar puede ser confuso hablar de asimetrías de información cuando las características del bien que se está transando son conocidas por ambas partes. Cuando las cuotas están 
definidas en forma autónoma, ambas partes de la transacción saben que lo único que se está transando es el derecho o permiso a capturar un porcentaje determinado de la cuota global que determine la autoridad. Y ambas partes están expuestas a la misma incertidumbre respecto de la cuota global que determinará la autoridad y de los precios de los productos finales a los que pueden acceder. En ese sentido las cuotas pesqueras (definidas en forma autónoma) son tan homogéneas como cualquier papel financiero ( $v . g r$. , acciones de una compañía), lo que facilita enormemente su transferibilidad.

En segundo lugar es importante explicar que esos analistas no están por prohibir la transferencia de cuotas fuera de las subastas - en un mercado secundario, tal como ocurre hoy día - y hacer de éstas la única forma en que una empresa podría obtener cuotas. Todo lo contrario, el desarrollo del mercado secundario es vital para alcanzar eficiencia productiva. El planteamiento es otro: que el mercado secundario no se puede desarrollar por falta de una señal fuerte de precios y que la única forma de levantar esa señal es vía subastas. Empíricamente vimos que esto no es así, pero igualmente es válida la pregunta: ¿Por qué recurrir a subastas para levantar esa señal? Si las pérdidas de eficiencia por la falta de un mercado secundario fuesen tan altas, habría amplias oportunidades para la aparición de uno o más intermediarios (market makers o brokers) y así se reducirían los costos de transacción y se facilitarían las transacciones socialmente eficientes.

Además que dichos intermediarios entregarían señales continuas de precios del mercado completo, a diferencia de las subastas, que serían espaciadas en el tiempo, quizá una vez al año, y parciales. Esto es precisamente lo que ocurrió, por ejemplo, en el mercado de permisos de contaminación de SO2 en Estados Unidos donde la señal de precios continua entregada por los intermediarios terminó por absorber la señal de precios que entregaba una subasta por una cantidad muy menor de la cuota global en el mes de marzo de cada año (Joskow et al., 1998).

Otro argumento que algunos dan en favor de las subastas, particularmente con relación a la asignación de permisos de contaminación, es que entregan más incentivos a la innovación en la reducción de costos de producción (v.gr., Cramton y Kerr, 2002; Milliman y Prince, 1989; Jung et al. 1996) ${ }^{33}$. Basados en el estudio de Milliman y Prince

${ }^{33}$ En ausencia de un mercado secundario, el precio que entrega una subasta parcial, es decir, de una fracción de la cuota, no necesariamente coincide con el precio de equilibrio del mercado completo. 
(1989), Cramton y Kerr (2002) argumentan que como la innovación reduce el precio de los permisos de contaminación, al subastarse los permisos las firmas no ven mermadas las rentas de escasez que significa la entrega gratuita de permisos y por lo mismo tienen más incentivos para innovar bajo un esquema de subastas. Hay dos problemas con esta afirmación. El primero es técnico. Tal como lo demuestran formalmente Montero (2002) y Requate (2005), los trabajos de Milliman y Prince (1989), al nivel de la firma, y más tarde de Jung et al. (1996), al nivel de la industria, cometen un error importante al confundir ahorros en costos con incentivos para innovar. Montero (2002) y Requate (2005) explican que lo importante para los incentivos para innovar es el precio de la cuota, que será el mismo, independiente del mecanismo de asignación inicial, tal como los mismos Cramton y Kerr (2002) lo indican. La explicación es simple: al realizar una innovación que reduzca los costos de abatimiento o las emisiones por unidad de producto, por ejemplo, la empresa gana lo mismo con la innovación, independiente de si significa comprar menos cuotas en caso de tener un déficit de cuotas o vender más si es que tiene un superávit. La ganancia es la misma si la firma es un comprador o vendedor de cuotas.

El segundo problema es de interpretación. Aun si aceptamos el argumento de mayor innovación en el caso de los permisos de contaminación, al llevar este argumento al caso de cuotas de pesca el resultado se invierte: la innovación es menor bajo un esquema de subasta porque la innovación hace subir el precio de las cuotas de pesca. Puesto que el precio de los productos finales está dado, una mejora en la eficiencia de captura lleva necesariamente a una valoración mayor de la cuota, y con ello, a mayores rentas de escasez. Aquí hay otra diferencia fundamental entre los permisos de contaminación y las cuotas de pesca que si no se toma en cuenta puede llevar a errores importantes de interpretación.

En esto de la innovación uno incluso podría plantear justo lo opuesto. Si el diseño de subasta es muy eficaz en extraer todas las rentas de escasez desde las firmas, las firmas tendrían pocos incentivos para innovar porque las rentas adicionales que la innovación genera se pierden con la próxima subasta. Ahora bien, si la subasta es un evento único de asignación inicial, tal como lo sería una asignación en base a captura histórica, los incentivos a la innovación, a partir de la asignación inicial, serían exactamente los mismos por las razones ya expuestas. 
Quisiera terminar esta discusión conceptual con la siguiente pregunta: ¿Cómo tendría que ser el diseño de la subasta para asegurarnos que efectivamente las cuotas caigan en manos de quienes más las valoren? Nadie ha demostrado que el diseño actual que se utiliza para asignar cuotas en las pesquerías de bacalao de profundidad, orange roughy, langostino colorado y langostino amarillo, el que básicamente incluye una subasta inicial por el total de la cuota seguida por subastas anuales por una fracción de aproximadamente $10 \%$ de la cuota global, efectivamente sea eficiente (véase PT\&F para una discusión más completa). La pregunta es relevante ya que tal como lo demuestra la literatura especializada (v.gr., Milgrom, 2004; Krishna, 2002), hay una tensión inevitable entre recaudación y eficiencia, la que se ve amplificada cuando lo que se subasta no es un objeto único indivisible (v. gr., obra de arte) sino múltiples objetos, en este caso homogéneos, como son cuotas de pesca ${ }^{34}$. Y la razón es que para lograr eficiencia el regulador tiene que sacrificar recaudación, es decir, dejar ciertas rentas con las empresas para que tengan incentivos a revelar en la subasta su verdadera valoración ${ }^{35}$.

En todo caso, no veo problemas de eficiencia si el regulador insiste en querer usar una subasta con fines recaudatorios, ya que cualquier ineficiencia que la subasta produzca en la asignación inicial va a ser corregida con las transacciones ex post que permiten la libre transferibilidad de las cuotas, tal como ocurriría con una asignación basada en captura histórica. Por eso dije al comienzo de esta sección que el uso, o no uso, de subastas para la asignación inicial de cuotas individuales es al final del día una discusión de economía política y no de libre competencia.

${ }^{34}$ Una subasta muy natural a usar en pesca es la subasta de precio uniforme de Wilson (1979), que busca repartir una cuota global entre varios oferentes (auction of shares) que entrega curvas de demandas por cuotas al licitador. Como es sabido (Milgrom, 2004), la subasta puede ser muy eficiente en la asignación pero resultar en nula recaudación, aun con un alto número de agentes y en ausencia de colusión.

${ }^{35}$ El ejemplo más simple es la subasta de segundo precio para un objeto único y con valoraciones independientes: el objeto se asigna al que más lo valora pero se le dejan rentas iguales a su valoración, menos la del segundo mejor postor. 


\section{Conclusiones}

En esta sección quisiera resumir los principales resultados y reflexiones de este trabajo. El primer resultado es que no se observan problemas de libre competencia en los mercados de productos finales (v.gr., harina de pescado, aceite de pescado, conservas), tanto internos como externos, en que participan las compañías pesqueras que tienen cuotas de pesca en la zona centro-sur. Hay varios elementos teóricos y empíricos que sustentan dicho resultado. Uno es teórico: ninguna compañía por iniciativa propia va a capturar menos que su cuota individual con el propósito de levantar los precios de los productos finales, a menos que haya un acuerdo colusivo de por medio, ya que tiene todos los incentivos para vender la parte de la cuota no utilizada a un tercero para así capturar una mayor fracción de las rentas oligopólicas en el mercado del producto final.

Hay además varios elementos empíricos. El primero es que los datos muestran que todas las cuotas asignadas han sido utilizadas; y en aquellos casos en que la captura ha caído por debajo de la cuota global ha sido por la menor disponibilidad de peces. El segundo es que las participaciones de ninguna de las compañías nacionales es suficiente como para mover por sí sola los precios de los productos finales en los mercados internacionales (i.e., externos). El tercero es que los mercados internacionales están lo "suficientemente cerca", pensemos en Perú, como para permitir que los precios de los productos finales en el mercado nacional (i.e., interno) se alejen de los niveles competitivos. Relacionado a esto último aparece un elemento adicional: De existir problemas de competencia en los mercados internos, una compañía pequeña como Lota Protein, que tiene el 1,8\% de la cuota global en la zona centro-sur, debiera vender el $100 \%$ de su producción en el mercado local; lo que observamos, sin embargo, es que parte importante de la producción de dicha compañía termina en mercados internacionales.

El segundo resultado es que no se observan problemas de libre competencia en el mercado de cuotas individuales de pesca en la zona centro-sur. Nuevamente hay elementos teóricos y empíricos que sustentan dicho resultado. Por una parte, el análisis teórico identifica un problema de inconsistencia temporal (análogo al de un monopolista de bien durable) que erosiona el poder de mercado de cualquier agente de 
tamaño importante, esto porque dicho agente no puede resistir volver al mercado a vender o comprar cuotas hasta alcanzar su asignación socialmente eficiente. El análisis teórico también muestra lo difícil que es alejarse de precios competitivos en un mercado de cuotas con varios agentes de tamaño importante y similares, ya que algunos de estos agentes estarán por el lado de la oferta, queriendo vender cuotas, mientras otros por el lado de la demanda, queriendo comprar cuotas. Por otra parte, los datos muestran un volumen y patrón de transacciones de cuotas que no son distintos a los que se observan en otras partes del mundo. El volumen de transacciones en un mercado de cuotas, en particular de transacciones de venta, no puede ser alto por la naturaleza de las transacciones: diferencias entre las valoraciones de largo plazo de las empresas.

Un tercer resultado, y muy relacionado a lo anterior, es que hay datos que muestran interesantes volúmenes de transacciones de arriendo de cuotas por períodos cortos (un año o menos) tanto en algunas pesquerías en Chile ( $v \cdot g r$., bacalao de profundidad, langostino colorado) como en las pesquerías de Nueva Zelanda. Este tipo de transacciones de corto plazo no puede surgir en el sistema de cuotas individuales establecido bajo la Ley 19.713 ya que estas últimas no pueden transferirse en forma autónoma, es decir, con prescindencia de la embarcación a la que fueron originalmente adscritas. La autoridad debiera entonces avanzar en la dirección de facilitar aún más la transferibilidad de las cuotas, tal como ocurre en las pesquerías anteriormente señaladas, ya que eso permitirá a las empresas realizar ajustes de corto plazo que, según la evidencia empírica, son importantes. Esta recomendación, que en su momento fue respaldada en el fallo del Tribunal de Defensa de la Libre Competencia a raíz de la causa levantada por Lota Protein, ya ha sido incorporada en el nuevo proyecto de Ley que está en discusión en el Congreso y que aparentemente goza de amplio apoyo. Esto permitirá reducir substancialmente los costos de transacción no sólo por permitir transacciones de corto plazo sino también al eliminar asimetrías de información que se generan al exigir transar cuotas junto a embarcaciones. Estos beneficios son independientes de si finalmente se decide o no utilizar subastas para asignar parte de las cuotas.

El último resultado es que desde el punto de vista de libre competencia no hace diferencia si la asignación de las cuotas individuales se 
realiza en base a capturas históricas o vía subasta. La ventaja inicial que consigue una subasta desaparece rápidamente: uno, porque los costos relativos de las empresas cambian y se requiere de nuevas transacciones, o dos, porque aun si los costos relativos no cambian, la libre transferibilidad permite acercarse al resultado de la subasta, si es eficiente, desde cualquier asignación inicial. Por lo mismo, el uso de subastas responde casi exclusivamente a motivos de recaudación y de distribución y ésa es una discusión de economía política que se aleja de los temas de libre competencia de este estudio.

\section{ANEXo}

\section{Competencia Cournot en el mercado nacional}

Siguiendo la notación del texto pero permitiendo que las compañías puedan tener cuotas y costos de extracción distintos, una firma cualquiera $j=1, \ldots, n$ en una competencia Cournot en el mercado nacional resuelve

$$
\operatorname{Max} P\left(q_{j}{ }^{n}+q_{-j}{ }^{n}\right) q_{j}^{n}+\left(p^{i}-t\right)\left(q_{j}^{T A C}-q_{j}^{n}\right)-c_{j} q_{j}^{n}
$$

donde $\mathrm{P}($.$) es la demanda en el mercado nacional, \mathrm{q}_{\mathrm{j}}{ }^{\mathrm{n}}$ es la venta de la empresa $j$ en el mercado nacional, $q_{j}{ }^{\text {TAC }}$ es la cuota recibida por la compañía $j, c_{j}$ es el costo de extracción y $q_{-j}{ }^{n}$ es la venta de todas las otras compañías exceptuando $\mathrm{j}$ en el mercado nacional. Resolviendo es fácil darse cuenta que en equilibrio todas las empresas venderán lo mismo en el mercado local independiente de su costo de extracción y cuota de extracción (a menos que esta última sea muy menor), lo que viene dado por

$$
\mathrm{q}_{\mathrm{j}}^{\mathrm{n}}=\left[\mathrm{P}\left(\mathrm{q}^{\mathrm{n}}\right)-\left(\mathrm{p}^{\mathrm{i}}-\mathrm{t}\right)\right] / \mathrm{P}^{\prime}\left(\mathrm{q}^{\mathrm{n}}\right) \leq \mathrm{q}_{\mathrm{j}}^{\mathrm{TAC}}
$$

donde $\mathrm{q}^{\mathrm{n}}=\mathrm{q}_{\mathrm{j}}{ }^{\mathrm{n}}+\mathrm{q}_{-\mathrm{j}}{ }^{\mathrm{n}}$ es la venta total en el mercado nacional. 


\section{REFERENCIAS}

Allaz, B., y J.-L. Vila (1993). "Cournot Competition, Forward Markets and Efficiency". Journal of Economic Theory 59, 1-16.

Anferova, E., M. Vetemaa y R. Hannesson (2005). "Fish Auctions in the Rusian Far East: A Failed Experiment”. Marine Policy 29, 47-56.

Bovenberg, A. L. y L. Goulder (1996). "Optimal Environmental Taxation in the Presence of Other Taxes: General Equilibrium Analysis". American Economic Review 86, 985-1000.

Clark, C. W. (1990). Mathemathical Bioeconomics. New York: WileyInterscience, 2nd Edition.

Coase, R. (1960). "The Problem of Social Cost". Journal of Law and Economics 3, 1-44.

(1972). "Durability and Monopoly". Journal of Law and Economics $15,143-149$.

Cramton, P. y S. Kerr (2002). "Tradeable Carbon Permit Auctions: How and why to Auction not Grandfather". Energy Policy 30, 333-345.

Eero, M., M. Vetemaa y R. Hannesson (2005). "The Quota Auctions in Estonia and their Effect on the Trawler Fleet". Marine Resource Economics 20, 101-112.

Gómez-Lobo, A., J. Peña-Torres y P. Barría (2007). “ITQ’s in Chile: Measuring the Economic Benefits of Reform”. Documento de Investigación, Depto. Economía, Universidad Alberto Hurtado.

Hahn, R. (1984). "Market Power and Transferable Property Rights". Quarterly Journal of Economics 99, 753-765.

Joskow, P. L., R. Schmalensee y E. M. Bailey (1998). “The Market for Sulfure Dioxide Emissions". American Economic Review, 88, 669-685.

Jung, C., K. Krutilla, y R. Boyd (1996). "Incentives for Advanced Pollution Abatement Technology at the Industry Level: An Evaluation of Policy Alternatives". Journal of Environmental Economics and Management 30, 95-111.

Kahn, C. M. (1986). “The Durable Goods Monopolist and Consistency with Increasing Costs". Econometrica 54, 275-294.

Krishna, V. (2002). Auction Theory. San Diego CA: Academic Press.

Liski, M. y J. P. Montero (2011). "Market Power in an Exhaustible Resource Market: The Case of Storable Pollution Permits". The Economic Journal 121, 116-144.

Lota Protein S.A. Consulta de la pesquera Lota Protein S.A. al Tribunal de Defensa de la Libre Competencia (sobre régimen de acceso a los recursos pesqueros) 2010. Disponible en www.tdlc.cl.

Malueg, D., y A. Yates (2009). "Bilateral Oligopoly, Private Information, and Pollution Permit Markets". Environmental and Resource Economics 43, 553-572.

Milgrom, P. (2004). Putting Auction Theory to Work. Cambridge, UK: Cambridge University Press.

Milliman, S. R. y R. Prince (1989). "Firms Incentives to Promote Technological Change in Pollution Control". Journal of Environmental Economics and Management, 17, 247-65. 
Montero, J. P. (1998). "Marketable Pollution Permits with Uncertainty and Transaction Costs". Resource and Energy Economics 20, 27-49. - (2002). "Permits, Standards, and Technology Innovation". Journal of Environmental Economics and Management 44, 23-44.

(2008). "A Simple Auction Mechanism for the Optimal Allocations of the Commons". American Economic Review 98, 496-518.

(2009). "Market Power in Pollution Permit Markets". The Energy Journal 30, 1-28.

- (2011). "Cuotas de pesca y libre competencia: Algunas reflexiones para la nueva ley de pesca". Documento de trabajo $\mathrm{N}^{\circ} 405$, Instituto Economía, PUC.

Newell, R., J. N. Sanchirico y S. Kerr (2005). "Fishing Quota Markets". Journal of Environmental Economics and Management 49, 437-462.

Peña-Torres, J. (2002). "Debates sobre cuotas individuales: ¿Privatizando el mar, subsidios o muerte anunciada de la pesca extractiva en Chile?" Estudios Públicos 86, 183-222.

Peña-Torres, J. y G. Fernández (2009). "Disuasión de entrada, subastas repetidas y divisibilidad del objeto en venta”. Documento de Investigación, Depto. Economía, Universidad Alberto Hurtado.

Requate, T. (2005). "Dynamic Incentives by Environmental Policy Instruments: A Survey". Ecological Economics 54, 175-195.

Salant, S. W., S. Switzer, y R. Reynolds (1983). "Losses from Horizontal Merger: The Effects of an Exogenous Change in Industry Structure on Cournot-Nash Equilibrium". Quarterly Journal of Economics 98, 185199.

Spulber, D. (1985). "Effluent Regulation and Long-Run Optimality". Journal of Environmental Economics and Management 12, 103-116.

Stavins, R. (1995). "Transaction Costs and Tradable Permits". Journal of Environmental Economics and Management 29, 133-148.

Tietenberg, T. (2003). "The Tradable-Permits Approach to Protecting the Commons: Lessons for Climate Change". Oxford Review of Economics Policy 19, 400-419.

(2006). Emissions Trading: Principles and Practice, Resources for the Future. Washington, D. C.: Resources for the Future (RFF) Press.

Wilson, R. (1979). “Auctions of Shares”. Quarterly Journal of Economics 93, 675-89. 